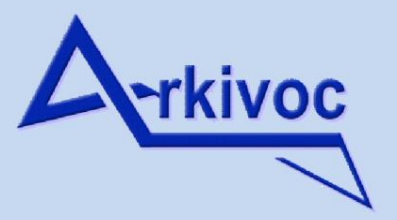

Archive for

Organic Chemistry
The Free Internet

Journal

Review

for Organic Chemistry

\title{
Site-specific synthesis and application of deuterium-labeled sterols
}

\author{
Hubert Muchalski* \\ Department of Chemistry, California State University, Fresno, \\ 2555 East San Ramon Avenue, SB 70, Fresno, CA 93740-8034, U.S.A. \\ Email:hmuchalski@csufresno.edu
}

This paper is dedicated to Professor Jacek Młochowski on the occasion of his $80^{\text {th }}$ birthday

Received 06-24-2016

Accepted 09-15-2016

Published on line 12-27-2016

\section{Abstract}

Isotopically-labeled compounds are universally accepted as very useful tracing molecules in chemistry and biology research. They are invaluable to support mechanistic hypotheses and measure reaction rates. Although they did not become mainstream until the early 1960s, numerous scientific contributions, have been made in areas of chemistry and biochemistry by using deuterium-labeled biomolecules. Deuterium-labeled sterols continue to be a primary research tool, particularly at the interface of chemical and biological sciences. This article surveys the literature on the use of deuterium-enriched sterol derivatives with a particular focus on synthetic strategies for incorporation of heavy isotopes.
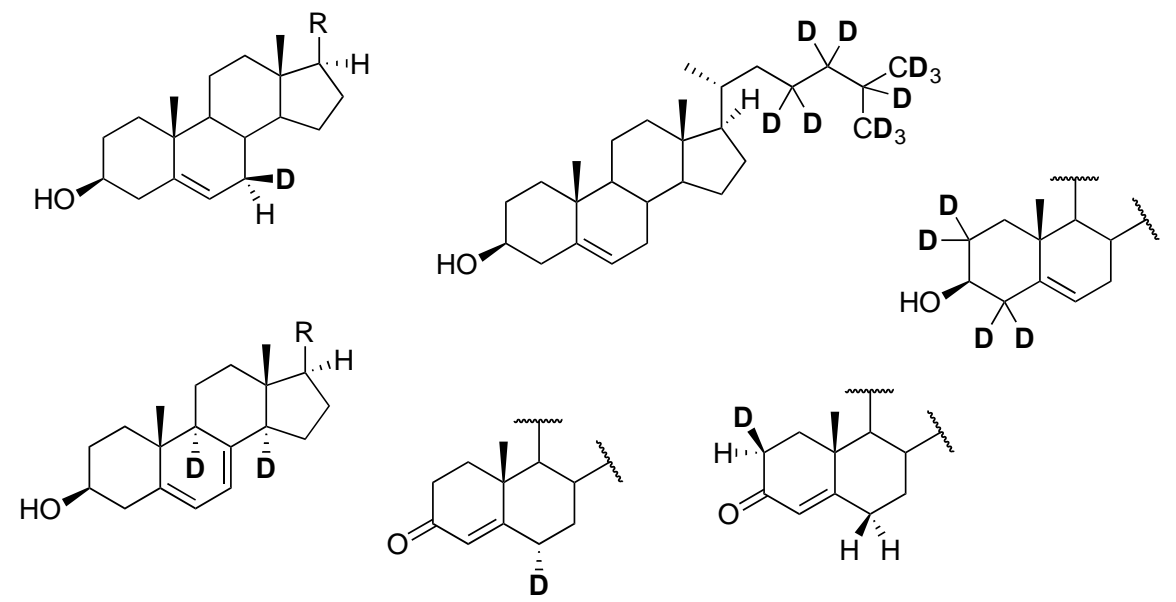

Keywords: Cholesterol, deuterium labeling, lipids, isotope labeling, sterols, kinetic isotope effect, deuteride 


\section{Table of Contents}

1. Introduction

2. Deuterated Steroids as Mechanistic Probes

\subsection{Applications in Chemical Reactions}

2.2. Applications in Biochemistry

3. Deuterated Sterols for Mass Spectrometry Applications

4. De Novo Approaches to Deuterated Steroids

5. Summary

References

\section{Introduction}

Isotope labeling of organic compounds is a very convenient approach to investigate mechanisms and kinetics of chemical and biochemical reactions. Their main advantage is that the reactivity of deuterium is the same as hydrogen, but it can be observed as a separate entity because of different mass (MS, IR) or magnetic properties (NMR). Interest in hydrogen isotope labeling for biochemistry experiments can be dated back to the 1930s. Labeling with radioactive tritium isotope was the dominant method for tracking biological processes until the early 1960 when mass spectrometry techniques started to become readily available.

Today, researchers across many fields and branches of physical and natural sciences continue to rely on deuterated sterols to answer research questions. In the last decade alone, deuterium-labeled sterols had been used to reveal how natural products interact with sterols in lipid bilayers, ${ }^{1,2}$ trace uptake of cholesterol by plants, ${ }^{3}$ and identify new oxysterol biomarkers of neurodevelopmental syndrome ${ }^{4-6}$ to name a few.

For the organic chemist, many commercially available deuterium-enriched building blocks as well as NMR solvents offer easy ways to introduce isotopically labeled functional groups in a single step. Many perdeuterated reagents such as methyl iodide, benzene, toluene, phenol, methylmagnesium bromide, benzyl bromide, etc. are commercially available. If the labeled hydrogen is acidic, H-D exchange can be accomplished by an acid-base reaction with deuterated solvents such as $\mathrm{D}_{2} \mathrm{O}$, methanol- $d$, or acetic acid- $d$. This strategy is sufficient if deuterium incorporation is pursued to alter the molecular weight for mass spectrometry applications but back-exchange with water can become a significant problem for quantitative measurements. Isotopic enrichment often requires multistep sequences or major detours in a synthetic plan because the exchanged atom is not directly accessible and the stereochemistry of the labeled position is often explicitly defined.

Site-specific deuterium incorporation into a steroid framework presents additional synthetic challenges. Steroids are primarily hydrocarbons that do not contain many functional groups that could assist in deuterium labeling. The most common functional groups in sterols are $\mathrm{C}-\mathrm{C}$ double bonds and alcohols. Double bonds can be easily reduced with catalytic $D_{2}$ addition. ${ }^{7}$ However, this reaction suffers from poor regioselectivity when multiple $\mathrm{C}-\mathrm{C}$ double bonds are present. For most common sterols, a hydroxy group is present only in ring $\mathrm{A}$ or on the side-chain. For cholesterol (1), for example, the majority of methods rely on redox chemistry of the C-3 alcohol or C-5 double bond. Oxidation of the C-3 alcohol to a ketone allows for base-catalyzed H-D exchange at C-2 and C-4. Additionally, conjugation with the C-5 double bond extends electrophilicity and acidity to ring B. For the most part, site-specific and stereoselective incorporation of a heavy isotope at other positions, especially in the C- and D-rings, remains difficult. 


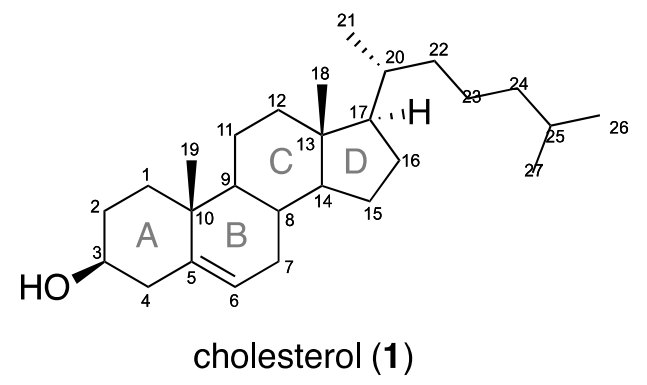

Figure 1. Numbering and ring labeling convention in cholesterol (1).

Deuterium-containing sterols are also indispensable in analytical applications, especially in mass spectrometry and NMR spectroscopy. Even before the advent of NMR and MS techniques, detection of deuterium was possible by infrared spectroscopy using the diagnostic absorption of carbon-deuterium bond (ca. $2100 \mathrm{~cm}^{-1}$ ). This technique not only aided isolation of deuterated intermediates but also allowed for semiquantitative analysis of heavy isotope content. In the last 50 years, mass spectrometry revolutionized biological sciences making deuterated steroids more relevant than ever. They are routinely used as internal standards in qualitative $\mathrm{e}^{3,8,9}$ and quantitative $\mathrm{u}^{4,6,8,10}$ measurements.

This review is an account of applications of deuterium-labeled sterol derivatives in chemistry and biochemistry with particular emphasis on synthetic methods and strategies for site-selective incorporation of a heavy atom into the steroid system. A body of work in the area of isotope labeling of steroid system appeared in the 1960s and had been comprehensively reviewed. ${ }^{7}$

\section{Deuterium-Labeled Sterols as Mechanistic Probes}

\subsection{Applications in Chemical Reactions}

The observation that cholesterol (1) undergoes H-D exchange was one of the first reports of deuteriumenriched sterols. Bloch and co-workers demonstrated that the molecular weight of cholesterol (1) increases after reaction with acetic acid- $d$ in the presence of a platinum catalyst. ${ }^{11,12}$ However, very little was known about the location and the degree of deuterium incorporation.

The demand for deuterated sterols grew steadily and was mostly fueled by interest in the role of steroid hormones in the function and regulation of various physiological processes. New methods for regio- and stereoselective labeling started to appear in the chemistry literature. Fukushima and co-workers demonstrated the first regioselective deuterium incorporation into the steroid system (Scheme 1). ${ }^{13}$ Selective allylic bromination of cholesteryl benzoate (2) followed by a reaction with deuterium gas in the presence of Raney nickel afforded 7- $d$-cholesterol benzoate (4). Alternatively, chromic acid oxidation of 2 leads to $\Delta^{5}-7$ ketone 5, which after conversion to thioketal 6 and desulfurization of with "deuterized" Raney nickel yielded $7,7-d_{2}-\Delta^{5}$-derivative 7 in $50-60 \%$ yield. 


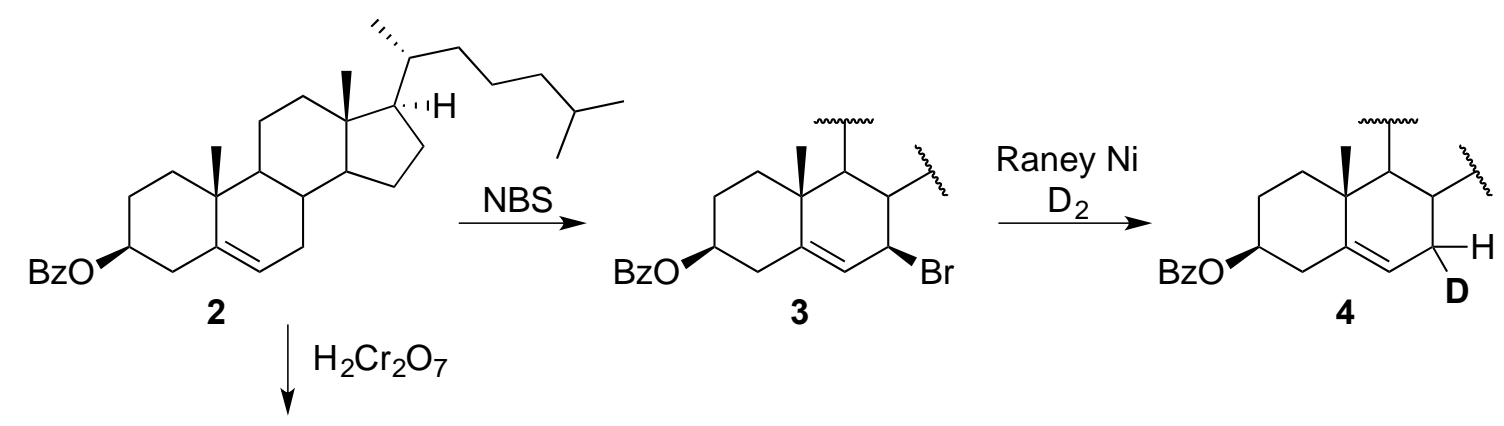

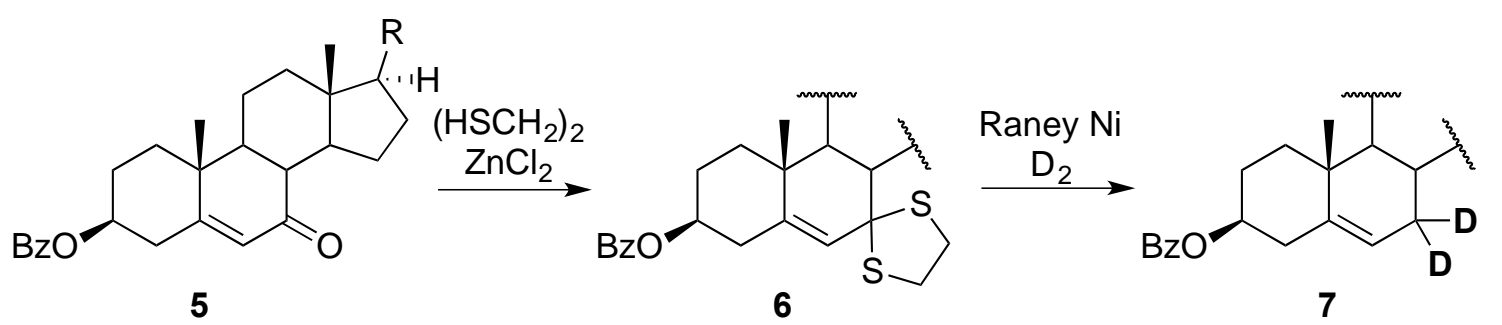

\section{Scheme 1}

As part of a systematic analysis of stereoelectronic control, Corey and Sneen used deuterium-labeled sterols to investigate the stereoelectronic factors controlling acid-catalyzed enolization of cyclic ketones. A high degree of stereoelectronic control was demonstrated in reactions of $3 \beta$-acetoxycholestan-7-one $(\mathbf{K})$ to the $\Delta^{6}$-en-7-ol (E). Although the axial hydrogen is sterically hindered, stereoelectronic factors favor its removal over the equatorial hydrogen by a factor of 12-50 depending on the acid catalyst used.

The synthesis of $6 \alpha-(\mathbf{1 0 a})$ and $6 \beta$-deutero-3 $\beta$-acetoxycholestan-7-one (10b) utilized in this study started with the conversion of $3 \beta$-acetoxy-7 $\alpha$-bromocholestan-6-one $(\mathbf{8})^{14}$ into epoxide $\mathbf{9}$ (Scheme 2). The ketone $\mathbf{8}$ was reduced with sodium borohydride, and the resulting bromohydrin was treated with zinc-acetic acid to afford the $\Delta^{6}$-alkene. Stereoselective epoxidation with peracetic acid provided the $\alpha$-epoxide 9, which was opened with lithium aluminum deuteride. The C-3 acetyl group was regioselectively restored, and the remaining C-7 alcohol was oxidized using chromium trioxide to give 10b. For the synthesis of 10a, the stereocenter at C- 6 was inverted by bromination of the enol tautomer of 10b, followed by debromination with

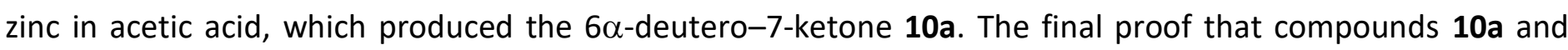
$10 \mathrm{~b}$ are epimers came from a slightly shifted $C-D$ stretching in IR spectrum which was also used to estimate isotopic purity of compounds $10 \mathrm{a}$ and $10 \mathrm{~b} .{ }^{15}$ 


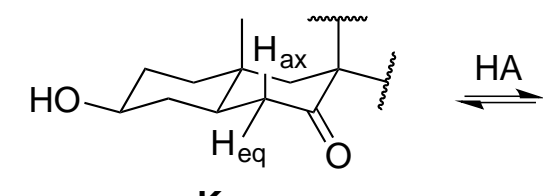

K

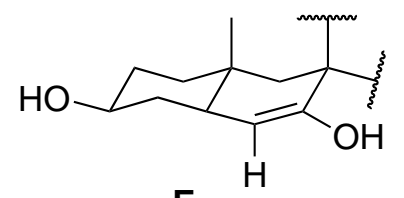

E

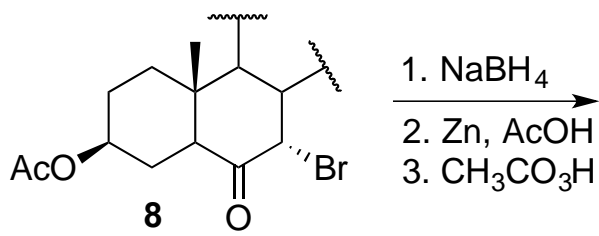<smiles>CC(=O)O[C@H]1CC[C@@]2(C)C3CCC3C(C(C)C)C3O[C@H]3C2C1</smiles>

1. $\mathrm{LiAID}_{4}$

2. $\mathrm{Ac}_{2} \mathrm{O}$, py

3. $\mathrm{CrO}_{3}$<smiles>[2H]C1C(=O)C(C(C)C)C(C)C2(C)CCC(OC(C)=O)CC12</smiles><smiles>[2H]C1C(=O)C(CC)C2CCCC2(C)C2CC[C@H](OC(C)=O)CC[C@]12C</smiles>

1. $\mathrm{Br}_{2}, \mathrm{CHCl}_{3}$

2. $\mathrm{Zn}, \mathrm{AcOH}$

\section{Scheme 2}

Cholesterol labeled with deuterium at C-4 was used to investigate the stereochemistry of a reaction of 4hydroxycholesteryl benzoate (11) with $\mathrm{SOCl}_{2}$, followed by reduction with $\mathrm{LiAlH}_{4}$ that gives cholesterol (1). At the time, the speculated pathway suggested chlorination at the $4 \beta$-position of cholesterol to give benzoate 12 . In the reaction with $\mathrm{LiAlH}_{4}$, the incoming hydride displaces the $4 \beta$-chloride and occupies the $4 \alpha$-position, implying an $\mathrm{S}_{\mathrm{N}} 2$ mechanism. Ireland and co-workers suggested ${ }^{16}$ that the reaction of 11 with $\mathrm{SOCl}_{2} \mathrm{proceeds}$ via an allylic carbocation and nucleophilic attack of the chloride results in regioselective chlorination at the $6 \beta$ position to give derivative 13. When treated with $\mathrm{LiAlH}_{4}$, the hydride attacks the $4 \beta$-position and displaces the chloride in an $\mathrm{S}_{\mathrm{N}} 2^{\prime}$ fashion (Scheme 3).

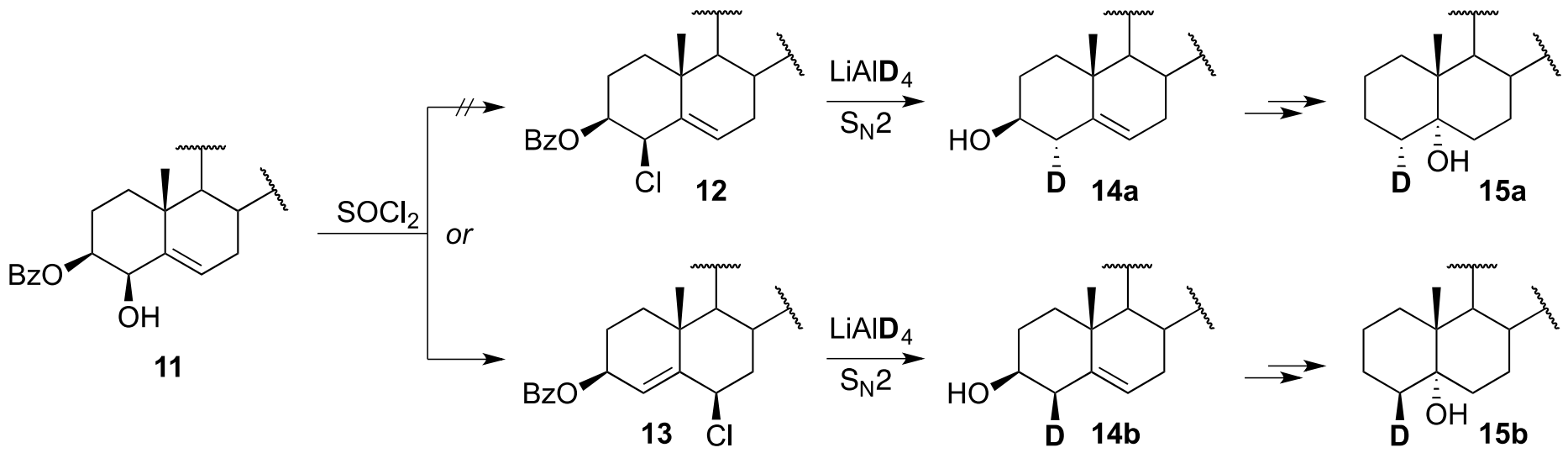

\section{Scheme 3}

To verify this hypothesis, the $4 \beta$-hydroxycholesteryl benzoate (11) was reacted with thionyl chloride, followed by treatment with LiAlD $_{4}$. Conversion to 5 -cholestanol ${ }^{15}$ and correlation to $\mathbf{1 5 a}$ and $\mathbf{1 5 b}$ revealed that the chlorination product is compound $\mathbf{1 3}$ with chlorine in the $6 \beta$-position (Scheme 3 ). ${ }^{17}$ The reference 
compounds $\mathbf{1 5 a}$ and $\mathbf{1 5 b}$ were synthesized via regioselective hydride opening of $4 \alpha, 5$-oxidocholestanes $1 \mathbf{8}^{17,18}$ and $19^{16}$ as depicted in Scheme 4.

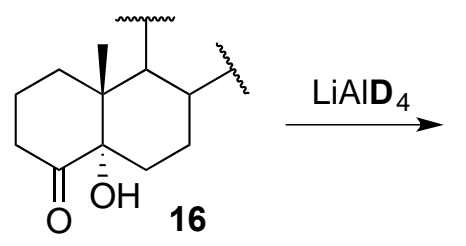<smiles>CCC1C(C(C)C)CC[C@]2(O)C(O)(O)CCC[C@]12C</smiles>

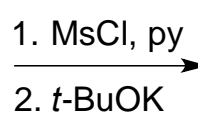<smiles>[2H][C@]1(O)CCC[C@]2(C)C(CC)C(C(C)C)CC[C@@H]12</smiles><smiles>CC(C)C1CCC2(O)C3CCCC[C@]2(C)C1C3C</smiles><smiles>[2H]C1CCC[C@@]2(C)C(CC)C(C(C)C)CC[C@]12O</smiles>

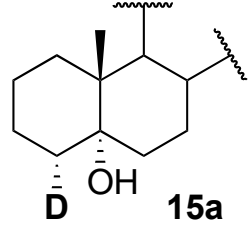

\section{Scheme 4}

While developing a general model for kinetic enolization behavior of $\alpha, \beta$-unsaturated ketones, Malhorta and Ringold studied the deuterium incorporation pattern in testosterone (20) under weak acid, strong acid, and strong base catalysis (Scheme 5). ${ }^{19}$ This work is a rare example of the use of an enzymatic reaction for analytical purposes. To determine the site of enol/enolate deuteration, the products were subjected to enzymatic dehydrogenation by Bacillus sphaericus that stereospecifically removes $1 \alpha-2 \beta$-hydrogens. Isotope distribution, as determined by a combination of IR and NMR analysis, demonstrated that strong acid led to the preferential but not exclusive formation of the thermodynamically more stable $\Delta^{3,5}$-enol (producing 21b), while weak acid and strong base favored the formation of the $\Delta^{2,4}$-enol/enolate (producing 22b).

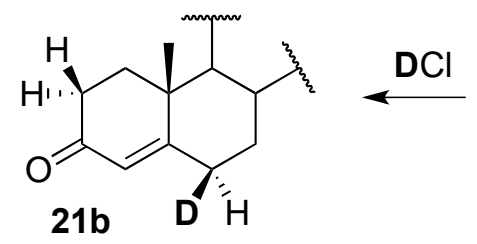<smiles>[H][Z]1([H])CC(C(C)C)C(CC)[C@]2(C)C[C@H](C)C(=O)C=C12</smiles>

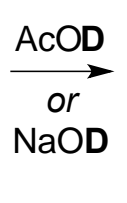<smiles>[2H][C@H]1C[C@@]2(C)C(CC)C(C(C)C)C[C@H]([2H])C(=CC1=O)[C@@H]2CC</smiles>

\section{Scheme 5}

Collins and co-workers used deuterated cholesterol to study the stereochemistry of proton removal during formation of $\pi$-allyl palladium complexes of 4 -en-3-ones within the rigid steroid skeleton. A reaction of sodium tetrachloropalladate(II) with cholest-4-en-3-ones stereospecifically labeled in positions $6 \alpha$ and $6 \beta$ provided convincing evidence that palladium binds to the $\alpha$-face and formation of the complex 23 results from highly stereoselective loss of the $6 \beta$-axial proton/deuterium (Figure 2). 


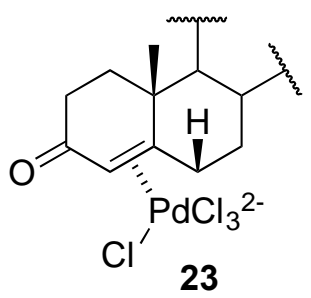

\section{Figure 2}

The authors found the synthesis of $6 \beta$-labeled cholest-4-en-3-ones by the method of Ringold ${ }^{19}$ to be unsatisfactory and opted for a modified version. The synthesis of the $6 \beta$-isomer $\mathbf{2 1 b}$ commenced with nonselective epoxidation of cholesterol and removal of undesired isomer by crystallization. Reduction of $\mathbf{2 4}$ with $\mathrm{LiAlD}_{4}$ and Jones oxidation gave hydroxy ketone $\mathbf{2 5}$ in $63 \%$ overall yield. To avoid chromatography of a compound with labile deuterium, the authors carried out dehydration with thionyl chloride-pyridine and purification by crystallization to afford the desired product in $47 \%$ yield (Scheme 6).

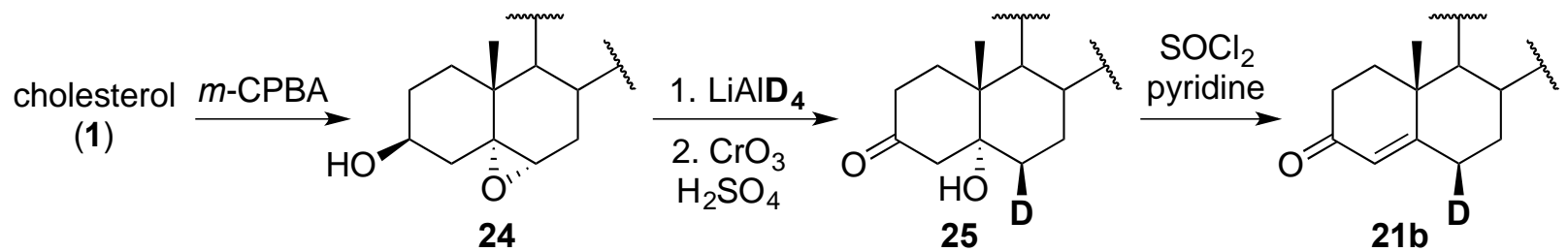

\section{Scheme 6}

Although the stereochemistry of the attack of carbon nucleophiles on steroidal palladium chloride complexes was well documented to occur at the $6 \beta$-axial position, ${ }^{21}$ the efforts to use this reaction to install a heavy isotope at C- 6 by reacting $\pi$-allyl palladium complexes with deuteride sources met with limited success. ${ }^{22}$ Rabinowitz and co-workers explored $\pi$-allyl chemistry to selectively label cholesterol at the C-4 $\alpha$ position. Reduction of cholest-5-ene-3 $\beta, 4 \beta$-diol cyclic carbonate 26 with sodium borodeuteride in the presence of $10 \%\left(\mathrm{Ph}_{3} \mathrm{P}\right)_{4} \mathrm{Pd}$ catalyst stereospecifically produced $4 \alpha$-d-cholesterol (14a) in $64 \%$ yield (Scheme 7). ${ }^{23}$
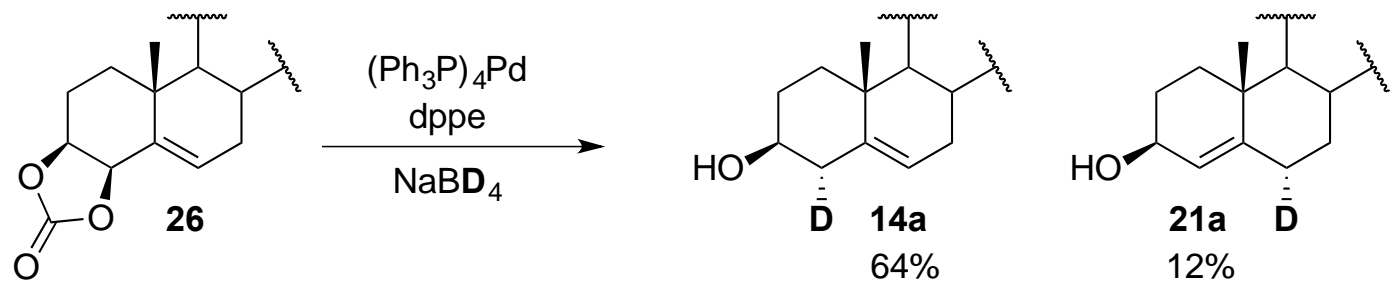

\section{Scheme 7}

Achmatowicz and Barton used deuterium-labeled probes to trace the stereochemistry of the photoelimination reaction of cholesteryl thiobenzoates. Irradiation of $O$-( $4 \alpha$-deuteriocholesteryl)thiobenzoate $\mathbf{2 7 a}$ gave the 3,5-diene $\mathbf{2 8 a}$ with complete retention of the label, whereas irradiation of the $4 \beta$-isomer $\mathbf{2 7}$ b resulted in complete loss of deuterium label (Scheme 8). ${ }^{24}$ 
<smiles>[Z17]CC(C)C1CC=C2[C@H]([2H])[C@@H](OC(=S)c3ccccc3)CC[C@]2(C)C1C(C)C</smiles><smiles>[R9]C1=CCC[C@]2(C)C1=CC[C@H](C(C)C)[C@H]2C(C)C</smiles><smiles>[R6][C@H]1C2=CC[C@H](OC(=S)c3ccccc3)[C@H]([2H])[C@@]2(C)CC[C@H]1C(C)C</smiles><smiles>CC(C)C1CC=C2C=CCC[C@]2(C)C1C(C)C</smiles>

\section{Scheme 8}

Cholesterols needed for this study, $\mathbf{1 4 a}$ and $\mathbf{1 4 b}$, were prepared from the corresponding alcohols (29, and 30) by employing the chlorination-reduction sequence developed previously by Ireland (Scheme 9). ${ }^{17}$ Allylic oxidation of cholesteryl benzoate (9) delivered alcohol 29, which was then reacted with $\mathrm{SOCl}_{2}$ followed by $\mathrm{LiAlD}_{4}$ to give the $4 \beta$-isomer 14b. To install the $4 \alpha$ deuterium, the alcohol in $\mathbf{2 9}$ was turned into a ketone, which was reduced with $\mathrm{NaBD}_{4}$ to yield the $4 \alpha-d$-alcohol $\mathbf{3 0}$. Compound $\mathbf{3 0}$ was converted into 14a by reaction with $\mathrm{SOCl}_{2}$ and then $\mathrm{LiAlH}_{4}$.

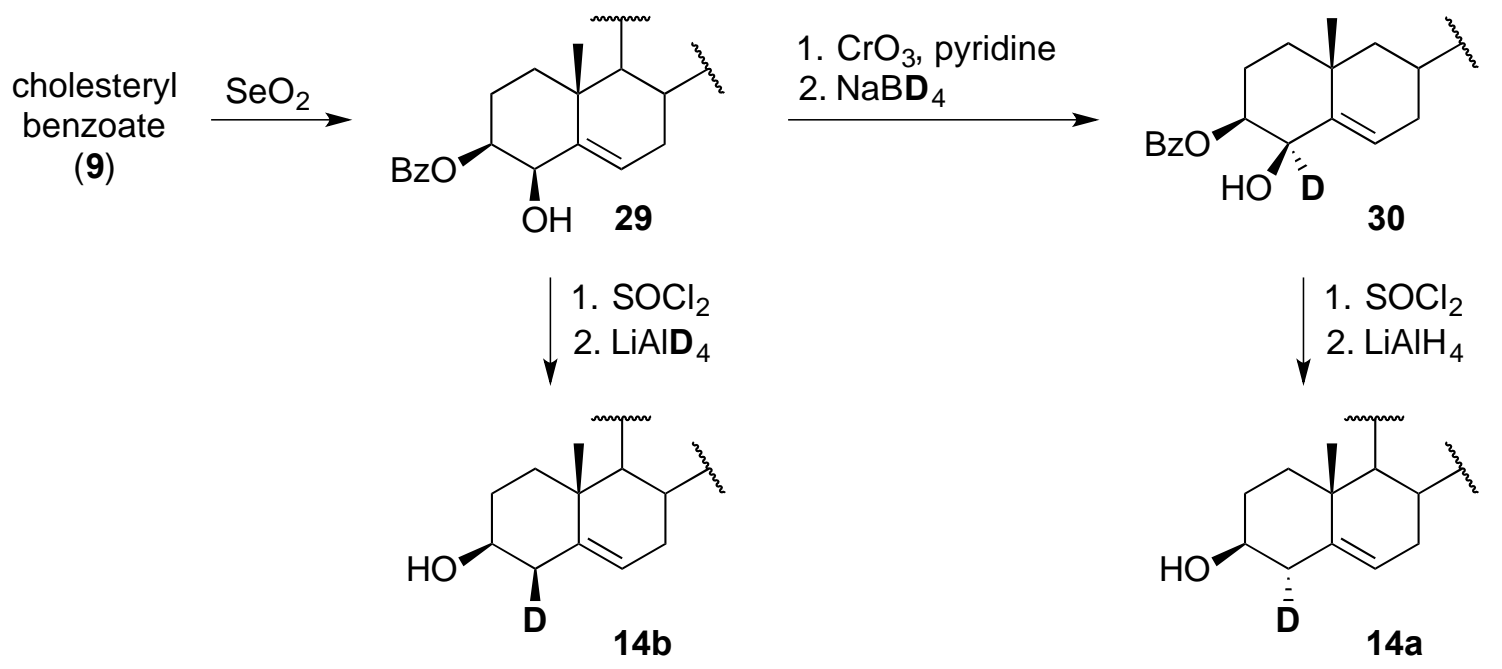

\section{Scheme 9}

The oxidation-reduction sequence (29 to 30), ${ }^{24}$ was later found to be difficult to replicate. Viger, Marquet, and the Barton group established that this borohydride reduction is sensitive to $\mathrm{pH}$, which can fluctuate due to variable amounts of $\mathrm{NaOMe}$ in the commercial reagent. During base-catalyzed enolate formation, the benzoyloxy group shifts from oxygen at $\mathrm{C}-3$ to one at $\mathrm{C}-4$. Protonation from the $\alpha$-face gives $4 \beta$ benzoyloxycholest-5-en-3-one (33), which then accepts a hydride/deuteride at C-3 carbonyl to give the compound $\mathbf{3 4}$ (Scheme 10). ${ }^{25,26}$ 
<smiles>CC=CCC1C(C(C)C)CC=C2C(O)=C(O)CC[C@@]21C</smiles>

31<smiles>[R16][C@H]1C(=O)CC[C@]2(C)C1=CC[C@H](C(C)C)[C@H]2C(C)C</smiles>

33<smiles>[R16][C@H]1C2=CCC(C(C)C)C(C(C)C)[C@@]2(C)CC[C@]1([2H])O</smiles>

34

\section{Scheme 10}

Šolaja and co-workers investigated the mechanism of the two-phase oxidation of steroidal 5-en-3 $\beta$-ols with the Jones reagent. Experiments with selectively labeled $4 \beta$-deuterocholesterol (14b), prepared using the method by Ringold and Ireland, ${ }^{17}$ indicated that the $\alpha$-hydrogen is removed exclusively during oxidation and suggests that there is no enolization before the reaction. Molecular mechanics (MM2) and semiempirical (PM3) calculations suggested that prior to the transfer of a hydrogen atom, ring A adopts a boat conformation to fulfill stereoelectronic demands for $\mathrm{H}$-atom abstraction. Radical $\mathbf{3 7}$ is the proposed intermediate in the formation of $\mathbf{3 5}$ (Scheme 11). ${ }^{27}$<smiles>[2H][C@@H]1C2=CCC(C(C)C)C(C(C)C)[C@@]2(C)CC[C@@H]1O</smiles>

$14 b$

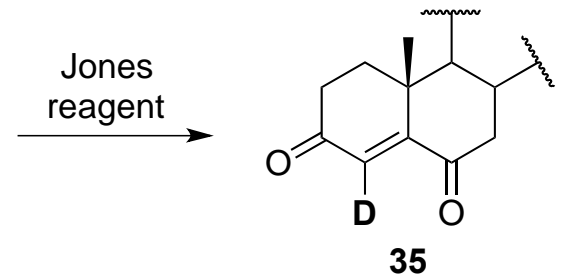

$36 a$<smiles></smiles>

$\mathrm{O}=$

H 36b<smiles>[2H]C1=C2C=CC(C(C)C)C(C(C)C)[C@@]2(C)CCC1=O</smiles>

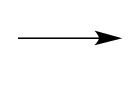

37<smiles>[2H]C1=C2C(=O)CC(C(C)C)C(C(C)C)[C@@]2(C)CCC1=O</smiles>

35

\section{Scheme 11}

\subsection{Applications in Biochemistry}

In the second half of the 1950s, much effort was directed at improving the understanding of enzyme-catalyzed transformations of steroidal compounds. The controlled hydroxylation of C-7 in steroids was of particular interest because this reaction occurs during the biosynthesis of cholic acid from cholesterol. For this purpose, Corey and Gregoriou developed stereospecific syntheses of the 7-deuterio and 7-tritiocholesterols (Scheme 12) to be used as substrates for enzymatic hydroxylation. Feeding rats with $7 \alpha$-labeled cholesterol resulted in only $7 \%$ retention of the label in metabolites. When $7-\beta$-labeled cholesterol was used, practically all label 
remained unreacted, suggesting that enzymatic hydroxylation of steroids at the saturated C-7 carbon doesn't occur via elimination and hydration of a $\mathrm{C}-\mathrm{C} \pi$ bond but rather by direct replacement mechanism.

Conversion of $\mathbf{8}$ into $\mathbf{3 8}$ was accomplished via stereoselective deuteration of the enol generated with $\mathbf{Z n -}$ $A C O D$. The B-ring unsaturation of cholesterol was restored by first reducing the ketone with sodium borohydride to $6 \beta$-alcohol, which was dehydrated with $\mathrm{POCl}_{3}-$ pyridine. Removal of the acetate at $\mathrm{C}-3$ with lithium aluminum hydride gave cholesterol-7 $\alpha-d$ (39a) in $73 \%$ yield over four steps. For the synthesis of the $\beta$ isomer, acid-catalyzed $\mathrm{H}-\mathrm{D}$ exchange in ketone $\mathbf{4 0}$ was followed by selective enol bromination and formation of $5 \alpha, 7 \beta-d_{2}-7 \alpha$-bromo-6-ketocholestanyl acetate (41). Using the same sequence as in the synthesis of $39 a$, the bromoketone 41 was converted into cholesterol-7 $\beta-d(39 b)$ in $97 \%$ isotopic purity.

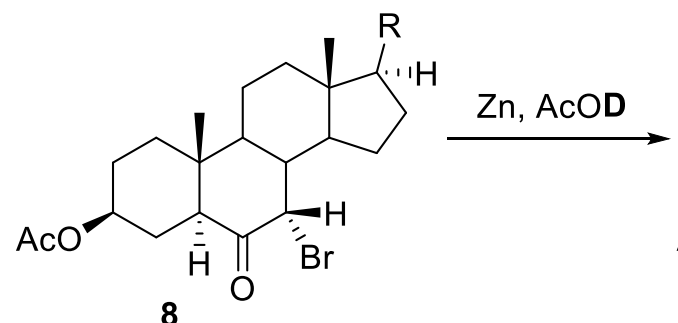

8 $\uparrow \mathrm{Br}_{2}, \mathrm{AcOH}$
40

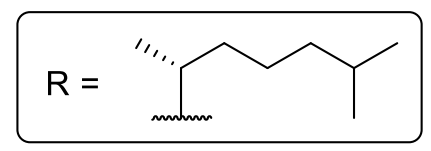

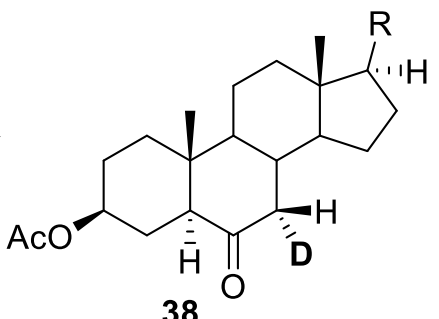

38 $\underset{\text { 2. } \mathrm{POCl}_{3} \text {, py }}{\stackrel{\text { paBH}}{\longrightarrow}}$

3. $\mathrm{LiAlH}_{4}$

1. $\mathrm{Zn}, \mathrm{AcOH}$

2. $\mathrm{NaBH}_{4}$

3. $\mathrm{POCl}_{3}$, py

4. $\mathrm{LiAlH}_{4}$<smiles>[R]C1CCC2C3CC=C4C[C@@H](O)CC[C@]4(C)C3CC[C@]12C</smiles>

$39 a$<smiles>[R]C1CCC2C3C(CC[C@]12C)[C@@]1(C)CC[C@H](O)CC1=C[C@H]3[2H]</smiles>

$39 b$

\section{Scheme 12}

In the 1970s new syntheses of deuteriocholesterols were developed to investigate the mechanisms of enzymatic transformations of sterols carried out by microorganisms. Nambara and co-workers developed routes to pairs of epimeric 2- and 4-deuteriocholesterols, as well as 6-deuterio-4-cholesten-3-ones to study the stereochemistry of hydrogen loss from C-2 and C-4 in enzymatic dehydration of cholesterol during biosynthesis of androsta-1,4-diene-3,17-dione. ${ }^{28}$ The main advantage of this synthesis (Scheme 13) is the latestage incorporation of deuterium. It requires, however, lengthy preparation of precursors 43-46. Aluminamediated elimination of the tosylate $\mathbf{4 2}$ was used to generate compound $\mathbf{4 3}$. The Alkene $\mathbf{4 3}$ is then converted into epoxide 44 in $64 \%$ yield. The epoxyacetate $\mathbf{4 4}$, available from cholesterol in 3 steps, was converted into tertiary alcohol $\mathbf{4 6}$ by hydrolysis, oxidation, and Huang Minlon deoxygenation. 
<smiles>CCC1C(C(C)C)CCC2(O)C[C@H](O[As])CC[C@]12C</smiles>

42

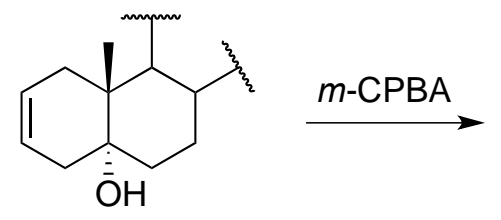

43<smiles>CCC1C(C(C)C)CC[C@]2(O)C[C@@H]3O[C@H]3C[C@]12C</smiles>

44<smiles>CCC1C(C(C)C)CCC2(O)C=CCC[C@]12C</smiles>

46

\section{Scheme 13}

Installation of deuterium from the $\alpha$-face of 43 and 46 was accomplished by a reaction with deuteriodiborane, generated from $\mathrm{LiAlD}_{4}$ and $\mathrm{BF}_{3}$, to provide the cis-addition products 47 and 48 . A transdiaxial epoxide opening of the $\alpha$-epoxides 44 and 45 with $\mathrm{LiAID}_{4}$ provided the $2 \beta$ - and $4 \beta$-deutero compounds 49 and 50. The configuration of the alcohol at C-3 in compounds 47-49 was inverted by oxidation-reduction sequence ( $\mathrm{CrO}-$ pyridine, $\mathrm{NaBH}_{4}$ ). Finally, all four diol diastereomers were dehydrated by treatment with $\mathrm{Ac}_{2} \mathrm{O}$ in pyridine to give cholesterol- $d$ diastereomers 14 and 51 (Scheme 14). ${ }^{28}$<smiles>CC(C)C1CCC(C)(O)C2(C)CC=CCC12C</smiles>

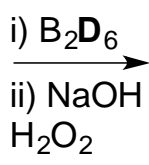<smiles>CCC1CCC2(O)C=CCC[C@]2(C)C1CC</smiles>

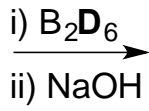

$\mathrm{H}_{2} \mathrm{O}_{2}$<smiles>[Te]=[TeH2]</smiles>

44<smiles>CC(=O)O[C@H]1CC[C@]2(C)C3CCC3C(C(C)C)CC[C@@]2(C)[C@H]1O</smiles><smiles>[2H][C@H]1C[C@@]2(C)C(CC)C(C(C)C)CC[C@]2(O)C[C@H]1O</smiles><smiles>[AsH3]</smiles><smiles>[AsH3][AsH3]</smiles>

D̄ ŌH 48<smiles>[2H][C@H]1C[C@]2(C)C(CC)C(C(C)C)CC[C@]2(O)C[C@H]1O</smiles>

4 steps

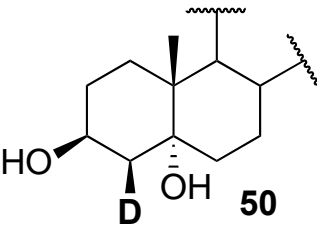

2 steps

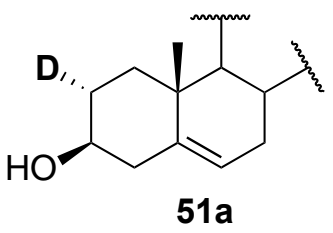

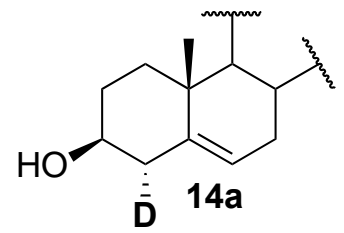<smiles>[2H][C@@H]1C[C@]2(C)C(=CCC(C(C)C)C2CC)C[C@H](O)[C@@H]1C</smiles><smiles>[2H]C1C2=CCC(C(C)C)C(CC)[C@@]2(C)CCC1O</smiles>

\section{Scheme 14}


Nambara and co-workers also synthesized epimeric 6-deuterio-4-cholesten-3-ones (21) to establish the stereochemical outcome of hydrogen transfer from C-4 to C-6 during enzymatic transformation of cholesterol into cholestenone. Using $\mathrm{LiAlD}_{4}$ as a deuterium source, cholesterol (1) was elaborated to 6-deuterio-4cholesten-3-ones $\mathbf{2 1}$ as shown in Scheme 15. Cholesterol epoxide $\mathbf{5 2}$ was treated with $\mathrm{LiAlD}_{4}$ to give diol $\mathbf{5 3 .}$ Chromium oxidation followed by acid-promoted dehydration afforded compound $\mathbf{2 1 b}$. Preparation of the $\alpha$ epimer 21a was carried out in similar manner by employing ketone $\mathbf{5 4}$. LiAID 4 reduction of $\mathbf{5 4}$ followed by Lewis acid-mediated cyclopropane opening afforded $6 \beta$-d-compound 55 that upon treatment with $m$-CPBA followed by $\mathrm{LiAlH}_{4}$, produced diol 56. Oxidation and dehydration of 56 yielded enone 21a. ${ }^{20}$

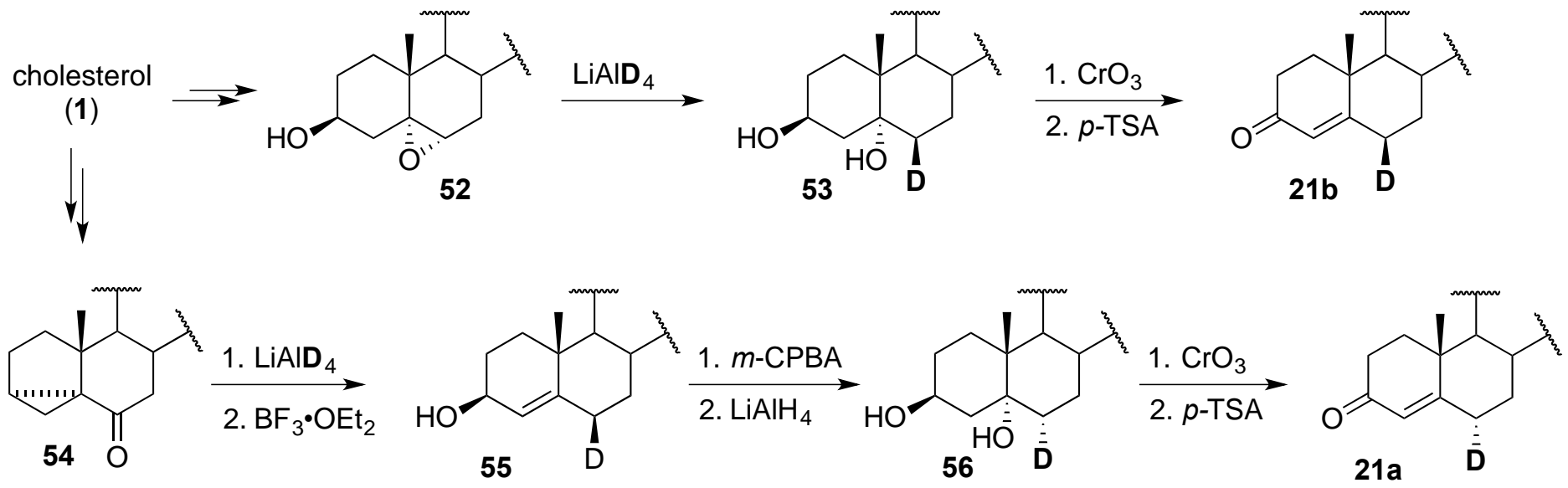

\section{Scheme 15}

Many sterols contain an unsaturated side-chain that terminates with two geminal methyl groups. Although chemically equivalent, the two methyl groups are nonequivalent in enzymatic oxidation reactions that lead to (25R)- and (25S)-26-hydroxycholesterol. Takeda and co-workers observed that 26- $\mathrm{H}$ and $27-\mathrm{H}$ are magnetically nonequivalent and synthesized (25S)-26- $d$ cholesterol to assign the pro- $S$ and pro- $R$ methyl groups by ${ }^{1} \mathrm{H}$ NMR.

The synthesis of (25S)-[26-d]-cholesterol began with diosgenin acetate (57) that had the C-25 chiral center assigned by X-ray analysis. After Clemmensen reduction of spiroketal in $\mathbf{5 7}$, which also removed the acetate, the alcohols at C-3 and C-26 were protected as $p$-nitrobenzoates. Jones oxidation and deprotection yielded compound 58. The ketone at C-15 was reduced using Huang Minlon deoxygenation conditions, and the C-3 alcohol was acetylated and the C-26 alcohol was converted into a tosylate. Upon treatment of 59 with LiAID the (25S)-[26- $d$ ]-cholesterol (60) was formed in 94\% isotopic purity (Scheme 16). ${ }^{29}$

The $(25 R)$ isomer was prepared in a similar manner starting from yamogenin acetate, a C-25 epimer of diosgenin. The identity of $(25 R)$ epimer was confirmed by Mosher ester analysis and by comparison to its epimer in reversed phase HPLC. ${ }^{30}$ 


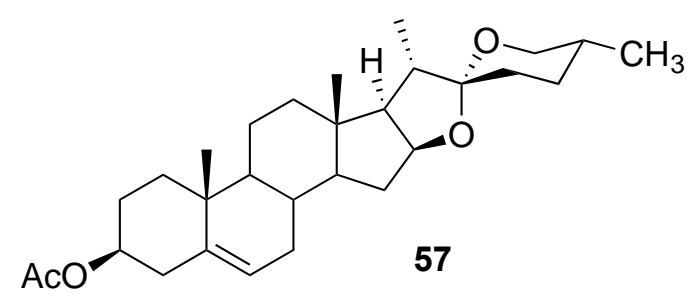

1. $\mathrm{Zn}(\mathrm{Hg}), \mathrm{HCl}$

2. $4-\mathrm{NO}_{2} \mathrm{C}_{6} \mathrm{H}_{4} \mathrm{COCl}$, py

3. $\mathrm{CrO}_{3}$, pyridine

4. $\mathrm{KOH}, \mathrm{MeOH}$<smiles>C[C@H](CO)CCC[C@H](C)[C@H]1C(=O)CC2C3CC=C4C[C@@H](O)CC[C@]4(C)C3CC[C@]21C</smiles>

\begin{tabular}{l} 
1. Huang Minlon \\
2. $\mathrm{TrCl}$, py, \\
then $\mathrm{Ac}_{2} \mathrm{O}$ \\
\hline 3. $\mathrm{HCl}$ \\
4. $\mathrm{TsCl}$, py
\end{tabular}
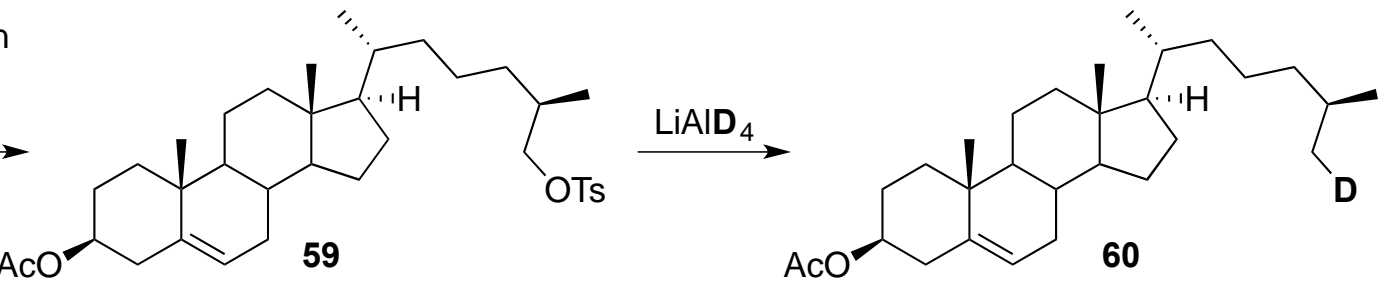

\section{Scheme 16}

Deuterated cholesterol and its metabolites were used to prove that cholesterol-induced down-regulation of hydroxymethylglutaryl-CoA reductase in mouse liver does not involve 24- or 27-hydroxylation. For that purpose 25,26,26,26,27,27,27- $d_{7}-24$-hydroxycholesterol (63) and 23,23,24,24,25-cholesterol- $d_{5}$ (64) were prepared as shown in Scheme 17. DIBAL reduction of cholenic acid methyl ester (61), followed by Grignard addition of isopropylmagnesium bromide-d gave compound 62. Using the same sequence, the mixture of epimeric alcohols 63 was prepared with isopropylmagnesium bromide- $d_{7}$ (Scheme 17). After oxidation of the secondary alcohol in $\mathbf{6 2}$ and $H-D$ exchange under acidic conditions (ACOD), the reaction mixture was treated with zinc amalgam in $\mathrm{DCl}$. The in-situ formed acetates were hydrolyzed with methanolic sodium hydroxide to give cholesterol- $d_{5} 64 .^{31}$

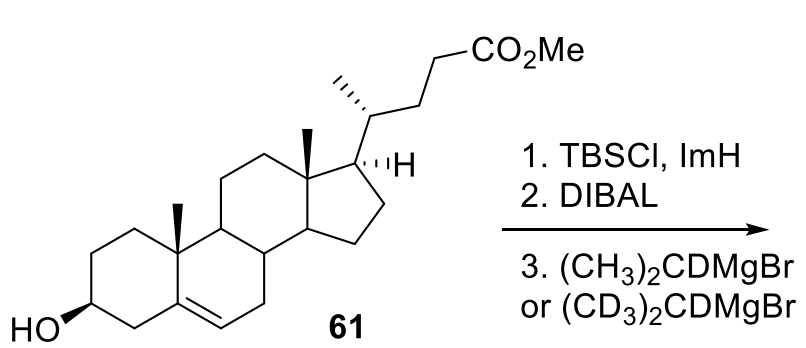

1. $\mathrm{PCC}, \mathrm{CH}_{2} \mathrm{Cl}_{2}$

2. AcOD

3. $\mathrm{Zn}(\mathrm{Hg}), \mathrm{DCl}]$

4. $\mathrm{NaOH}, \mathrm{MeOH}$

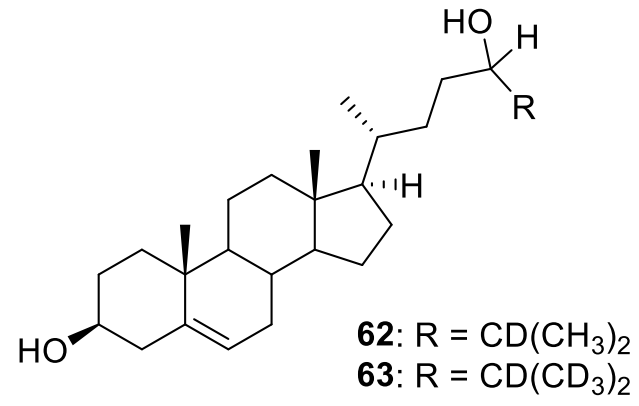

63: $\mathrm{R}=\mathrm{CD}\left(\mathrm{CD}_{3}\right)_{2}$

\section{Scheme 17}<smiles>[2H]C([2H])(C)C([2H])([C@H](C)[C@H]1CCC2C3CC=C4C[C@@H](O)CC[C@]4(C)C3CC[C@]21C)C([2H])([2H])C</smiles> 
Morisaki and co-workers prepared 24- $d$-desmosterol (67) to follow the stereochemical outcome of reduction of the $\mathrm{C}-24,25$ double bond in the enzymatic conversion of desmosterol into cholesterol. Using deuterium-decoupled ${ }^{1} \mathrm{H},{ }^{13} \mathrm{C}$ shift correlation $\mathrm{NMR}$ analysis of the biosynthesized cholesterol they demonstrated that the stereospecific incorporation of hydrogen atoms occurs from the re-face of the C-24 position of desmosterol. Aldehyde 65 , derived from binorcholenic acid in four steps, ${ }^{32}$ was reacted with a stabilized ylide in a Horner-Emmons olefination to give $\alpha, \beta$-unsaturated ester. Hydrogenation of the $C-C$ double bond followed by reduction of the ester with LiAID $_{4}$ afforded the $24-d_{2}$ alcohol 66 . Ley oxidation, Wittig olefination, and deprotection produced 24-d-desmosterol (67). Yields of reactions, however, were not reported (Scheme 18). ${ }^{33}$
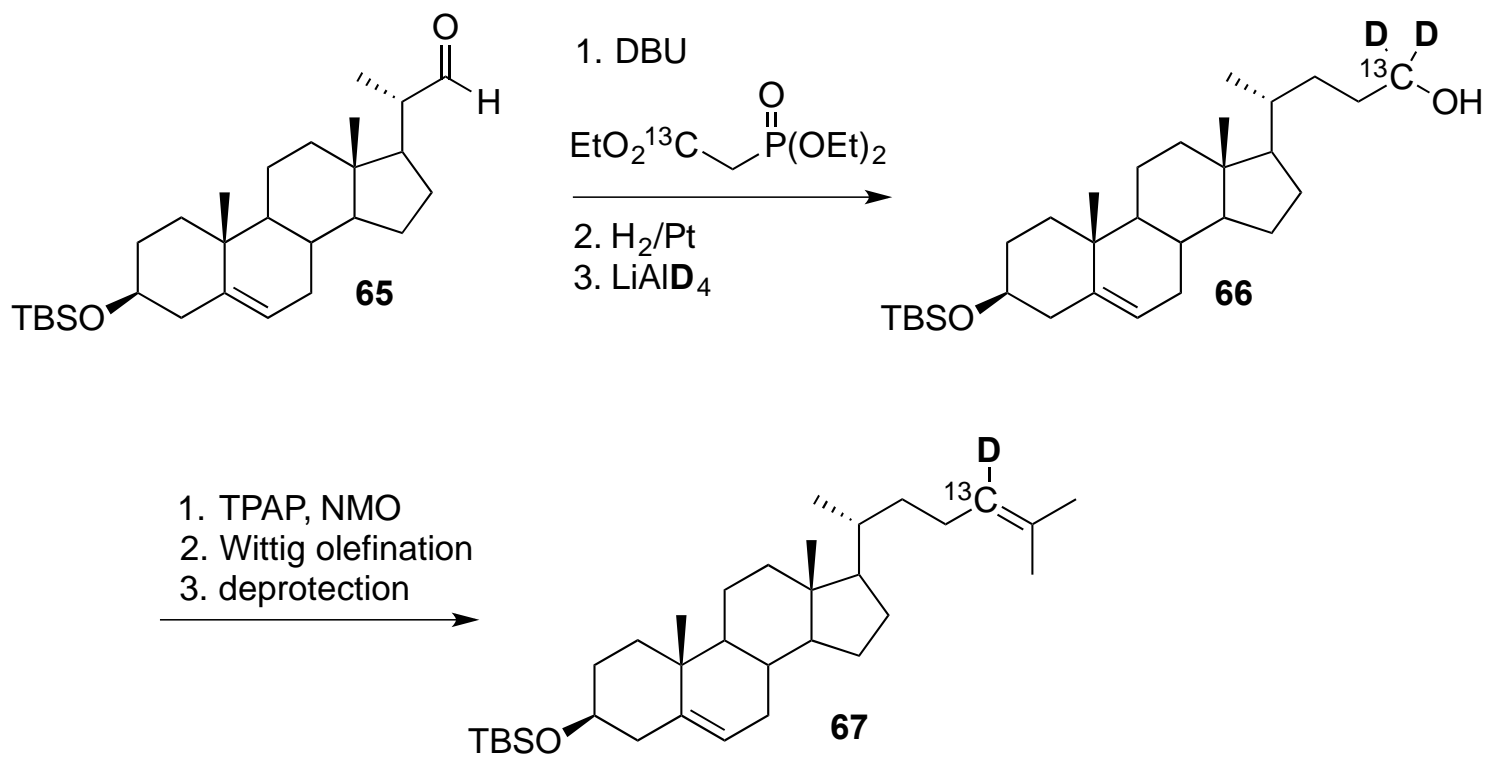

\section{Scheme 18}

\section{Deuterated Sterols for Mass Spectrometry Applications}

The development of mass spectrometry techniques, especially when coupled with gas chromatography, made it possible to identify and quantify lipids in biological samples. However, GC/MS methods did not become commonplace until the pathways of fragmentation of steroid skeleton were fully characterized. In the mid1960s four different fragmentation modes were proposed for the characteristic M-85 ion and one for the formation of $\mathrm{M}-111$. However, preliminary deuterium labeling data disproved all of them and suggested alternative pathways (A, B; Figure 3). To establish the exact cleavage patterns and find evidence to support the mechanism of these fragmentations it was necessary to examine mass spectra of various deuterium-labeled analogs. In 1977, Wyllie, Amos, and Tökés published a systematic MS analysis of 11 deuterium labeled sterols, which revealed a very complicated fragmentation patterns observed in the steroid field to date. They showed that characteristic ions in mass spectra are strongest when the $\mathrm{C}-5$ double bond is present and not as it was postulated, by C-3 alcohol or ketone. The ions are detected even in spectra of $\Delta^{5}$-steroids without a hydroxy or keto group at C-3. 


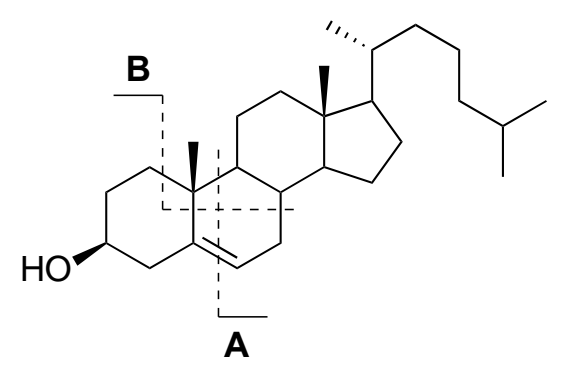

\section{Figure 3}

2,2,4,4- $d_{4}$ - and 2,2,4- $d_{3}$-Cholesterol (69 and 71, respectively) were prepared as previously reported. ${ }^{34}$ During base-catalyzed H-D exchange and deconjugation of enone 20, the intermediate enolate 68 can be selectively deuterated with ACOD at C-4 over C-6. Reduction of deconjugated ketone afforded 2,2,4,4,- $d_{4-}$ cholesterol 69. Alternatively, intermediate 68 can be trapped as enol acetate 70 and reduced with $\mathrm{NaBH}_{4}$ to give 2,2,4- $d_{3}$-cholesterol 71 (Scheme 19).

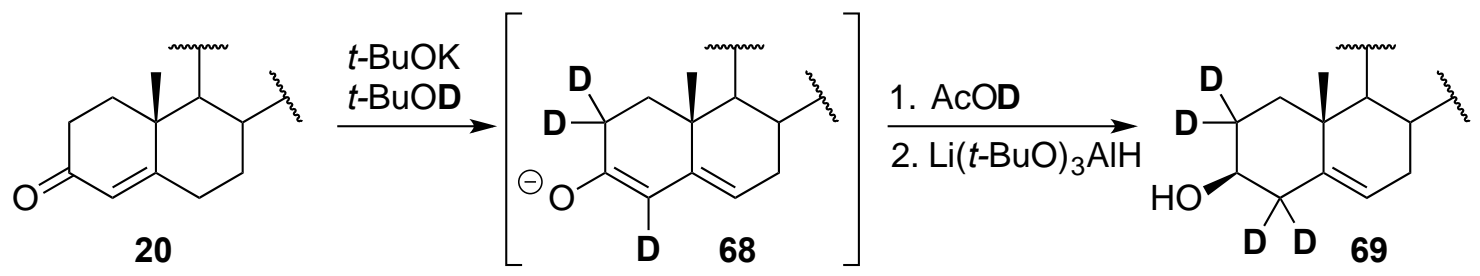

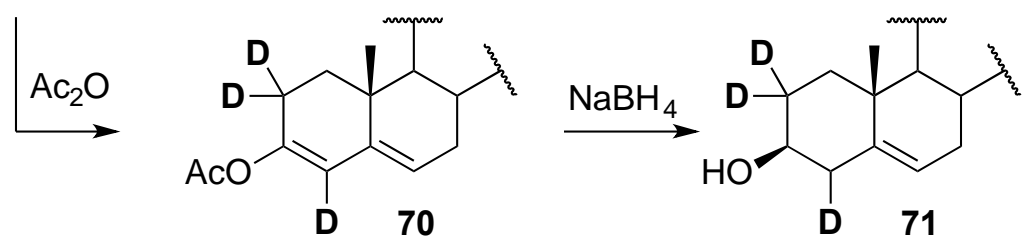

\section{Scheme 19}

Both the $\alpha$ and $\beta$ hydrogens at C-1 were installed by catalytic deuteration of the C-1 double bond in cholesta-1,4-dien-3-one (72) as shown in Scheme 20. Homogeneous reduction catalyzed by Wilkinson's catalyst afforded compound 73a. ${ }^{35}$ Base-catalyzed back-exchange at $\mathrm{C}-2$, deconjugation, ${ }^{19,34,36}$ and reduction with $\mathrm{NaBH}_{4}$ led to $1 \alpha$-d-cholesterol (74a). The same sequence carried out with heterogeneous catalyst $\mathrm{Pd} / \mathrm{C}$ yielded the $1 \beta$ - $d$-cholesterol (74b).

Elaboration of the ketone in 3 $\beta$-hydroxy-5 $\alpha$-cholestan-6-one THP ether (75) was used to install the vinyl deuterium at C- 6 of cholesterol. Reduction of 75 with LiAlD $_{4}$ produced alcohol 76, which after dehydration and THP deprotection, yielded 6- $d$-cholesterol 77. When hydrogens at C-5 and C-7 in 75 were exchanged with deuterium prior to reduction with $\mathrm{LiAlH}_{4}$, dehydration, and deprotection yielded 7- $d_{2}$ derivative 80 (Scheme 21). ${ }^{35}$ 
<smiles>[2H][C@H]1[C@@H]([2H])C(=O)C=C2CCC(C(C)C)C(C(C)C)[C@]21C</smiles>

73b<smiles>CC(C)C1CCC2=CC(=O)C=C[C@]2(C)C1C(C)C</smiles>

72

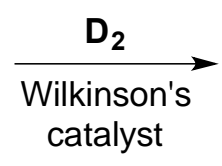

catalyst<smiles>[2H][C@@H]1C(=O)C=C2CCC(C(C)C)C(C(C)C)[C@@]2(C)[C@H]1[2H]</smiles>

$73 a$ $\underset{\text { 1. } \mathrm{H}-\mathrm{D} \text { exchange }}{\text { 2. deconjugation }}$
3. $\mathrm{NaBH}_{4}$

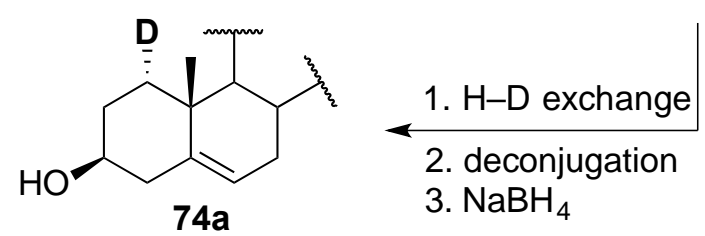

\section{Scheme 20}

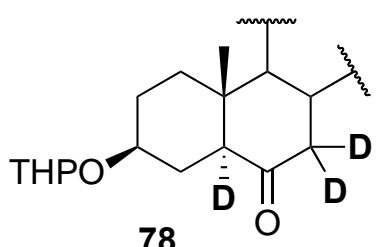

78

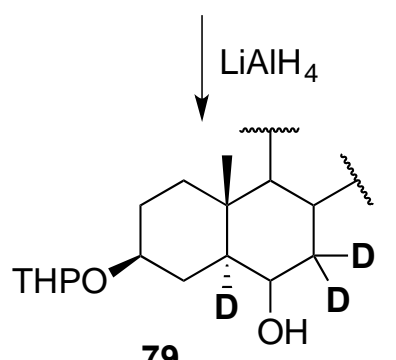

79

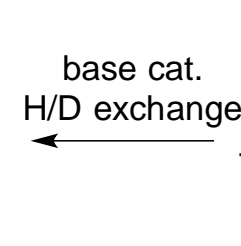<smiles>CCC1C(C(C)C)CC(=O)C2CC([Po])CCC21C</smiles>

75

1. dehydration

$$
\text { 2. THP }
$$
deprotection

\section{Scheme 21}

Deuterium labeling of the $8 \beta$-position was accomplished by base-catalyzed H-D exchange at C-6/8 in cholestan-7-one acetate $\mathbf{8 1}$ to give $\mathbf{8 2}$, although extended reaction time was required due to a reluctant exchange of the $8 \alpha$-hydrogen. The main disadvantage of this approach is the laborious sequence required to restore cholesterol unsaturation in the B-ring. Upon conversion into tosylhydrazone and reduction with sodium borohydride, the derivative $\mathbf{8 3}$ formed without significant deuterium loss. The C-3 alcohol was oxidized and $\alpha, \beta$-unsaturation was introduced by a bromination-elimination sequence to give 84 . Deuterium atoms at C-6 in 84 were back-exchanged, and the enone was deconjugated and reduced with sodium borohydride (Scheme 22). 
<smiles>CCC1C(=O)CC2C[C@@H](O)CC[C@]2(C)C1C(C)C</smiles>

81

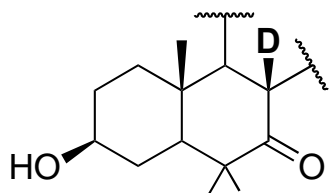

82
1. $\mathrm{TsNHNH}_{2}$

2. $\mathrm{NaBH}_{4}$

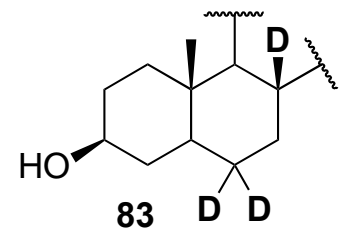
1. Jones
2. $\mathrm{pyH}^{+} \mathrm{Br}_{3}^{-}$
3. $\mathrm{LiCl}, \mathrm{DMF}$

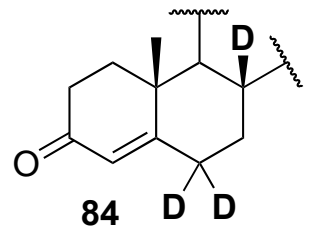

$\frac{\text { 1. } \mathrm{H} / \mathrm{D} \text { exchange }}{\text { 2. } t-\mathrm{BuOK}}$
3. $\mathrm{NaBH}_{4}$<smiles>CC1CCC2(C)C1CC=C1C[C@@H](O)CC[C@]1(C)C2C</smiles>

\section{Scheme 22}

The label at the $9 \alpha$-position was installed via Birch reduction of enone $86 .{ }^{37}$ As was the case in the $8 \beta$ labeled derivative, transformation into $9 \alpha$-d-cholesterol (90) required seven additional steps (Scheme 23). The acetate at C-3 was hydrolyzed, the ring-C ketone was removed using Wolff-Kishner reduction, and the C-3 alcohol was oxidized to give ketone $\mathbf{8 8}$. Bromination-elimination provided enone $\mathbf{8 9}$ which was deconjugated and reduced to give $9 \alpha$ - $d$-cholesterol (90).

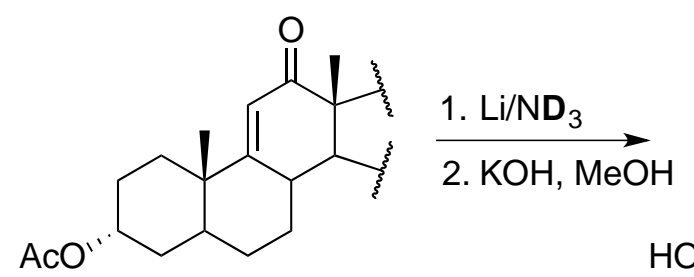

86<smiles>CC1C(CO)[C@@]2(C)C(=O)CC3C(CCC12)C1CC[C@@H](O)CC[C@@]13C</smiles>

87 $\underset{\text { 1. Wolff-Kishner }}{\stackrel{\text { Jones oxidation }}{\longrightarrow}}$

2. Jones oxidation<smiles>CC1CC2C3CCC4CC(=O)CC[C@]4(C)C3CCC2(C)C1C</smiles>

88

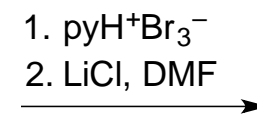

1. $\mathrm{pyH}^{+} \mathrm{Br}_{3}^{-}$
2. $\mathrm{LiCl}, \mathrm{DMF}$

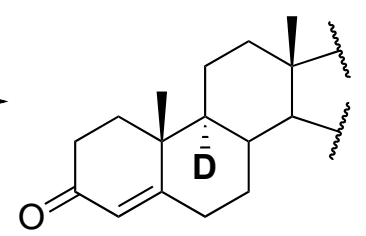

89

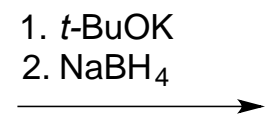<smiles>CC1C2CC=C3C[C@@H](O)CC[C@]3(C)C2CCC1(C)C</smiles>

90

\section{Scheme 23}

The C-19 analog 92 was prepared by reduction of the aldehyde functional group in pregn-5-ene-3 $\beta, 20 \beta$ diol-19-al THP ether (91). Although deuteride reduction of the aldehyde is quite difficult, it can be achieved by electrochemical reduction in strongly acidic medium (Scheme 24). ${ }^{38}$<smiles>CCC1C(C(C)C)CCC2(O)C[C@@H]([Po])CC[C@@]12C=O</smiles>

91

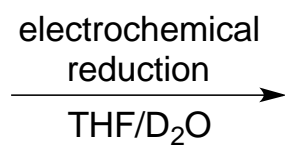

$\mathrm{THF} / \mathrm{D}_{2} \mathrm{O}$<smiles>CCC1CCC2C[C@@H](O)CC[C@]2(C)C1CC</smiles>

92 
Mass spectrometry techniques that allow for accurate quantitation of cholesterol continued to develop. This, in turn, increased the demand for multi-deuterated cholesterol derivatives used as mass-offset standards. Such compounds should be at least two mass units heavier than the analyte and contain a high level of isotope incorporation that is not exchangeable. Although the syntheses of cholesterol-2,2,4- $d_{3}$ and cholesterol-2,2,4,4- $d_{4}$ were already reported, ${ }^{34}$ the degree of isotope incorporation was unsatisfactory for quantitative applications. In 1978 Gruenke and Cymerman reported an improved method for the synthesis of cholesterol- $d_{2}(94)$ and cholesterol- $d_{5}$ (97). Conversion of $\Delta^{4}$-cholesten-3-one (20) to the enol acetate 93 followed by reduction with sodium borodeuteride in deuterated methanol yielded cholesterol-3,4- $d_{2}(\mathbf{9 4})$. Base-catalyzed H-D exchange, before conversion to enol acetate and reduction, allows for the preparation of 97 (Scheme 25). ${ }^{39}$<smiles>CCC1C(C(C)C)CC=C2C=C(OC(C)=O)CC[C@@]21C</smiles>
93

$\mathrm{ROAC}$ cat. $\mathrm{H}_{2} \mathrm{SO}_{4}$<smiles>CCON=CC(C)C1CCC2=CC(=O)CC[C@]2(C)C1CC</smiles>

20

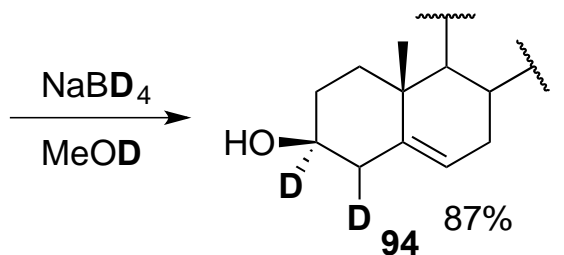

4<smiles>[2H]C1=C2C([2H])([2H])CC(C(C)C)C(CC)[C@@]2(C)CC([2H])([2H])C1=O</smiles>

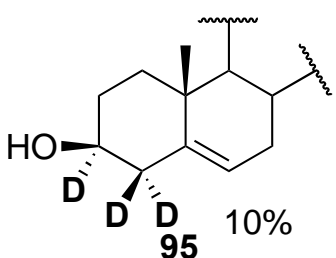

9

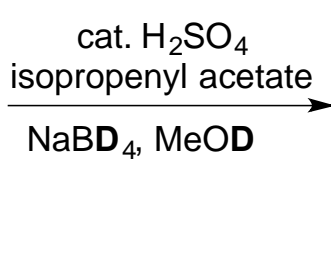

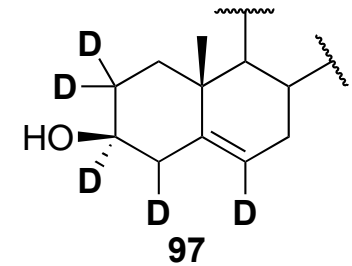

\section{Scheme 25}

A selective isotope labeling of the 24-position in lanosterol (101) was disclosed by Raab and co-workers in 1968. ${ }^{40}$ Lanosterol acetate (98) was treated with a stoichiometric amount of $\mathrm{OsO}_{4}$ and the resulting osmate ester was reduced with sodium sulfite in ethanol to give the corresponding diol. The secondary alcohol was acetylated to give compound $\mathbf{9 9}$ which was followed by a reaction with zinc and sodium borodeuteride to give compound 100. Dehydration and deprotection yielded lanosterol-24-d (101, Scheme 26). This sequence was later used by Zhou and co-workers to prepare $\mathbf{1 0 1}$ to study the mechanism of migration of H-24 in lanosterol during biosynthetic transformation into ergosterol. ${ }^{41}$

Kirk and co-workers reported a synthesis of 26,27- $d_{6}$-cholesterol (105) from the corresponding desmosterol. The Julia olefin synthesis proved to be superior to Wittig reaction in the preparation of the key intermediate, desmosterol- $d_{6}(\mathbf{1 0 4})$. The reaction of sulfone 102 with LDA followed by addition of acetone- $d_{6}$ gave hydroxysulfone 103 in $81 \%$ yield. Treatment of 103 with sodium amalgam in methanol-THF followed by THP deprotection gave desmosterol- $d_{6} 104$ in ca. $40 \%$ yield (Scheme 27$) .{ }^{42}$ 

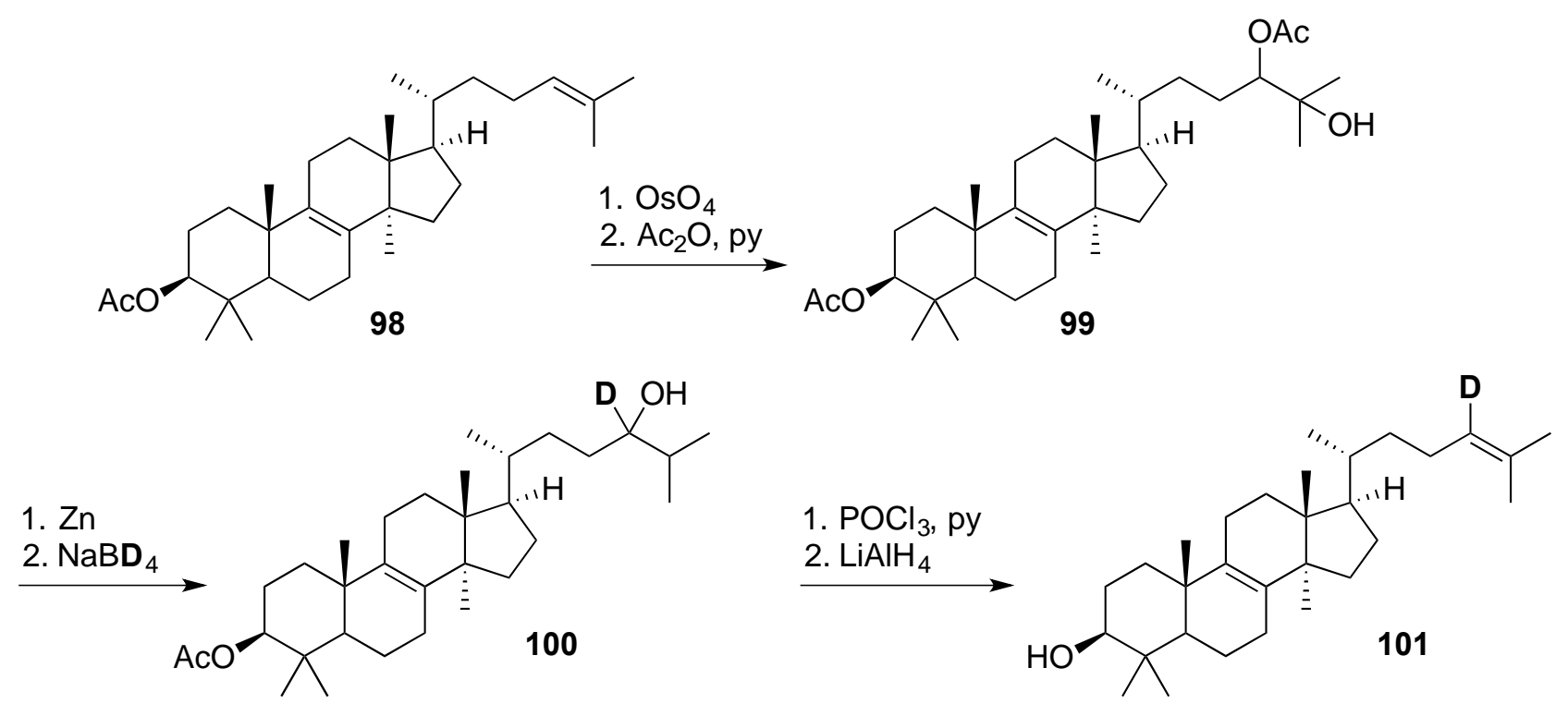

\section{Scheme 26}<smiles>C[C@H](CCCS(=O)(=O)Oc1ccccc1)[C@H]1CCC2C3CC=C4C[C@@H]([OH+])CC[C@]4(C)C3CC[C@]21C</smiles>

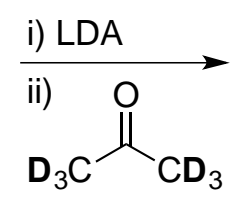

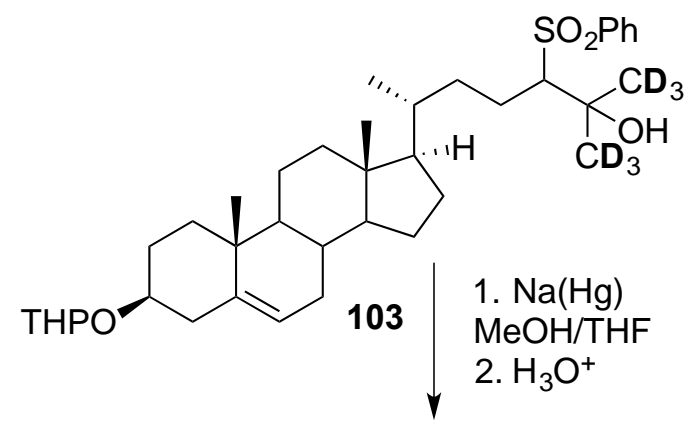

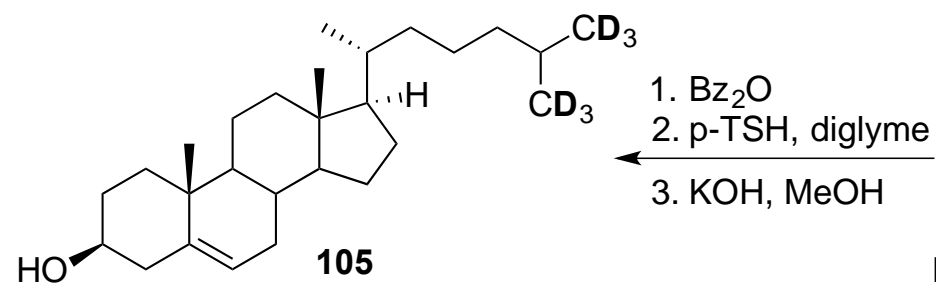<smiles>C[C@H](CCC=C(C(C)(C)C)C(C)(C)C)[C@H]1CCC2C3CC=C4C[C@@H](O)CC[C@]4(C)C3CC[C@]21C</smiles>

\section{Scheme 27}

Conversion of desmosterol- $d_{6}(\mathbf{1 0 4})$ to cholesterol- $d_{6}(\mathbf{1 0 5})$ was difficult. Although the $\Delta^{24,25}$ double bond could be selectively hydrogenated over the B-ring unsaturation, it came at the cost of significant scrambling of isotope label. However, when converted into a benzoate, the reaction with diimide (in-situ produced by thermolysis of $p$-toluenesulfonylhydrazide, $p$-TSH) produced cholesteryl benzoate with only slight loss of deuterium (2\%). Preparative HPLC followed by alkaline hydrolysis of the benzoate provided cholesterol- $d_{6}$ (105) in 38\% yield over two steps (Scheme 28 ). ${ }^{42}$

The synthesis of hexadeuterocholesterol using the above procedure was not widely adopted because of the high cost of the starting material (desmosterol). In the follow-up work, Crossland and Holm reported an improved method that used pregnenolone as a starting sterol. Isopropylmagnesium bromide- $d_{6}$ derived from acetone- $d_{6}(\mathbf{1 0 6})$ was reacted with allyl bromide to yield 4-methylpentene- $d_{6}(107)$. anti-Markovnikov addition of $\mathrm{HBr}$ produced the primary bromide, which, upon reaction with triphenylphosphine, gave phosphonium 
bromide 108. A Wittig reaction with pregnenolone TMS ether 109 delivered desmosterol- $d_{6} \Delta^{20}$-cholesterol. The side-chain unsaturation was reduced using hydrogen and platinum oxide at atmospheric pressure to yield hexadeuterocholesterol (110) in 7\% overall yield from pregnenolone (Scheme 28). ${ }^{43}$
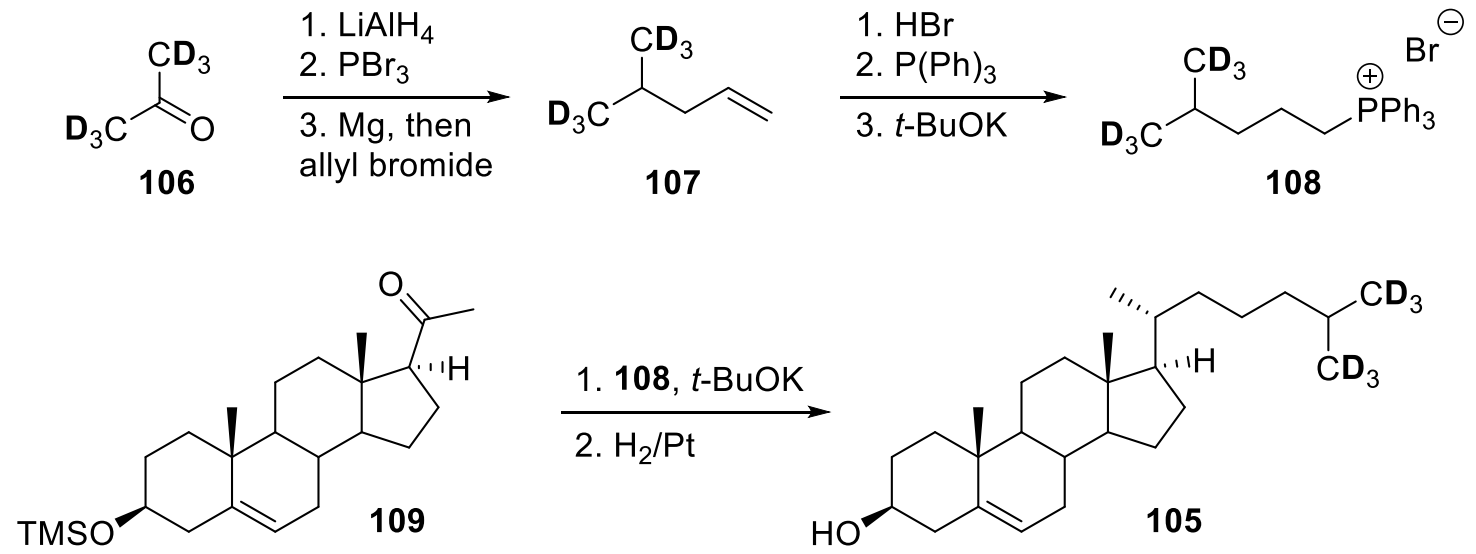

\section{Scheme 28}

Wasilczuk and co-workers developed a more streamlined synthesis of desmosterol- $d_{8}$ and cholesterol- $d_{9}$ to monitor cholesterol oxidation products related to atherosclerosis. After H-D exchange of $\alpha-$ protons in ketone 110, it was reacted with $\mathrm{CD}_{3} \mathrm{MgBr}$. The resulting tertiary alcohol was converted into a bromide to give 111. Bromide $\mathbf{1 1 1}$ was reacted with Raney nickel and the resulting $1: 1$ mixture of desmosterol- $d_{8}(\mathbf{1 1 2})$ and cholesterol- $d_{9}$ (113) was separated by reversed-phase preparative HPLC (Scheme 29). ${ }^{44}$

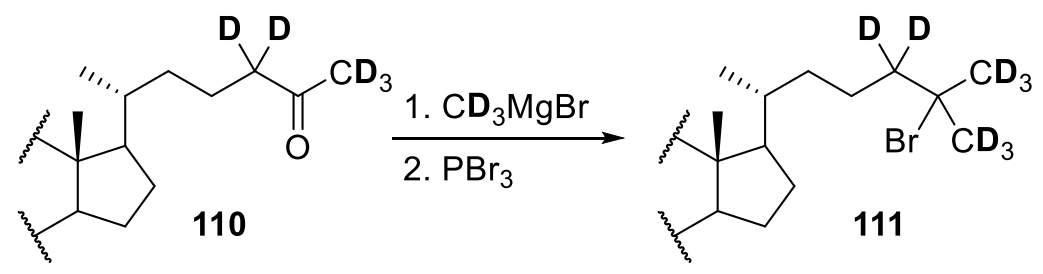

\section{$\underset{\text { 1. Raney-Ni, } \mathbf{D}_{2}}{\stackrel{\mathrm{NaOD}, \mathbf{D}_{2} \mathrm{O}}{\longrightarrow}}$}
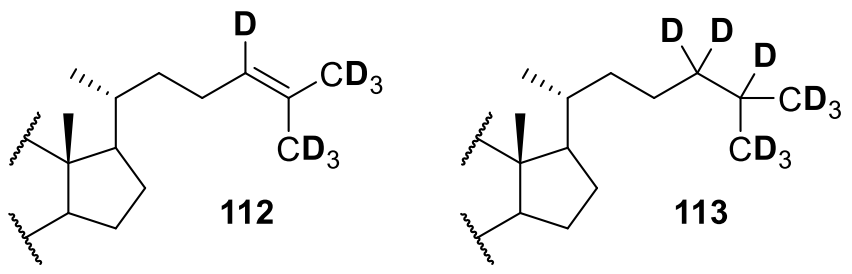

\section{Scheme 29}

In 2013, Bittman and Baek developed an improved synthesis of sterols with deuterated sidechains. ${ }^{42,43,45,46}$ The carbanion generated from cyano sterol $\mathbf{1 1 4}$ was alkylated with isopentyl- $d_{11}-4-$ methylbenzenesulfonate and the nitrile group in $\mathbf{1 1 5}$ was reductively removed with excess potassium metal and crown ether in toluene to give cholesterol- $d_{11}(\mathbf{1 1 6})$ (Scheme 30). ${ }^{47}$ 


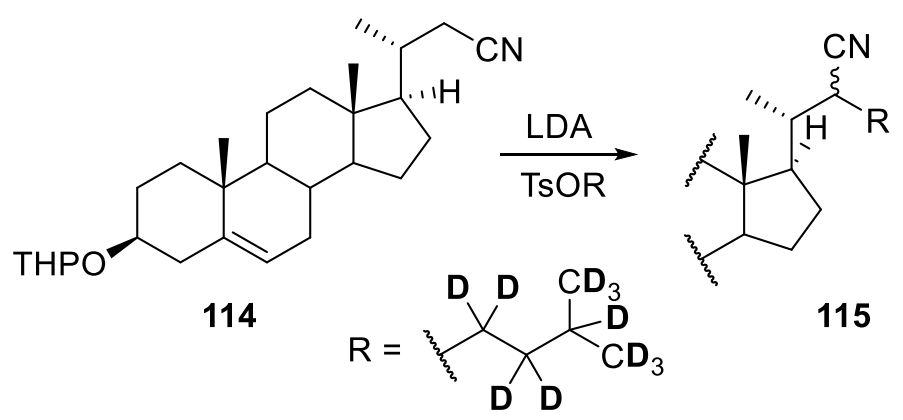

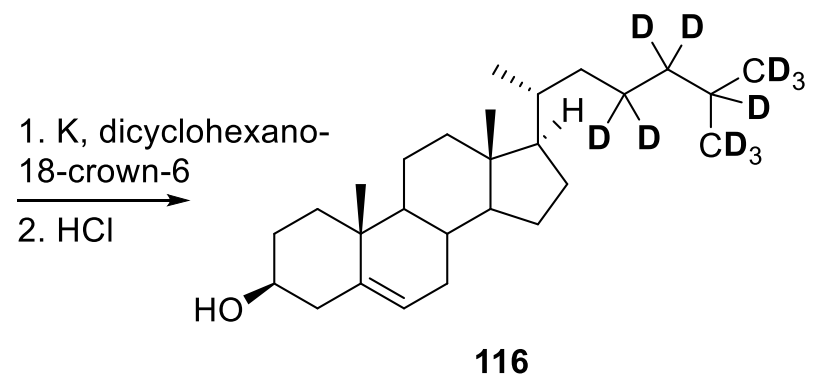

\section{Scheme 30}

Miura and co-workers disclosed the most recent report on the synthesis of deuterated sterols. Synthesis of $2 \beta, 3 \alpha, 6-d_{3}$-cholesterol (121) is achieved by simultaneous opening of epoxide and reduction of C- 6 ketone in 118. The synthesis involves multiple steps but reported yields for most reactions in the sequence are good (Scheme 31). ${ }^{48}$<smiles>[R]C1CCC2C3CC=C4C[C@@H](O)CC[C@]4(C)[C@H]3CC[C@]12C</smiles>

1

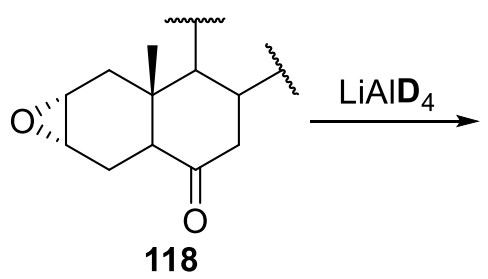

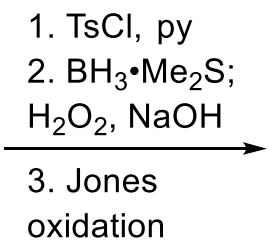<smiles>[2H][C@@H]1C[C@]2(C)C(C[C@H]1O)[C@H](C)[C@H](C(C)C)C[C@]2([2H])O</smiles>
119<smiles>CCC1C(C(C)C)CC(=O)[C@@H]2C[C@@H](O[AsH3])CC[C@]12C</smiles>

117
1. collidine

2. $m$-CPBA

1. Jones oxidation

2. $\mathrm{NaBD}_{4}, \mathrm{MeOH}$

3. TBSCl, py

1. $\mathrm{POCl}_{3}$, py

2. $\mathrm{HCl}$<smiles>[2H]C1=C2C[C@]([2H])(O)[C@@H]([2H])C[C@]2(C)C(C(C)C)C(C(C)C)C1</smiles>

121

\section{Scheme 31}

\section{De Novo Approaches to Deuterated Steroids}

Steroids have also been targets of few de novo approaches, ${ }^{49}$ but the incorporation of isotope label is rarely the main justification for constructing the entire steroid framework. However, de novo synthesis remains the only option when the level of deuterium incorporation is low or the position is not directly accessible. 
As part of their effort towards the total synthesis of ent-cholesterol, Rychnovsky and co-workers prepared an analog with a fully deuterated C-19 methyl group (Scheme 32). The deuterium label was introduced during reductive alkylation of enone $\mathbf{1 2 2}$. Treatment of $\mathbf{1 2 2}$ with lithium in liquid ammonia followed by alkylation of the enolate with $\mathrm{CD}_{3}$ l, provided compound 123 in $66 \%$ yield. The ketal was deprotected under acidic conditions and the resulting ketone used to construct the A ring via intramolecular aldol condensation. Deconjugation and reduction of the enone yielded $19-d_{3}$-ent-cholesterol (124) in $70 \%$ yield over the 3 steps. ${ }^{50}$
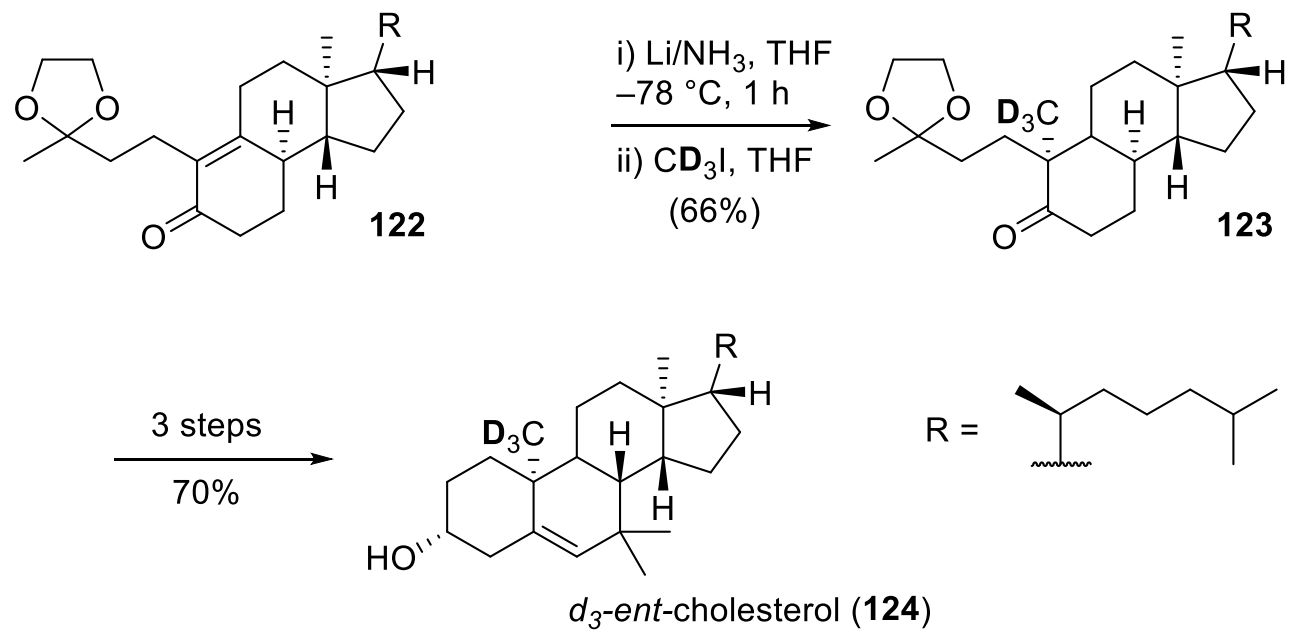

\section{Scheme 32}

$\mathrm{H}$-Atom transfer to propagating peroxyl radical is the rate-determining step in radical chain oxidation. The rate constant for certain polyunsaturated fatty acids is very high $\left(k_{\mathrm{p}}\right.$ of arachidonic acid being $\left.197 \mathrm{M}^{-1} \mathrm{~s}^{-1}\right)$. It has also been suggested that quantum tunneling contributes to the high rate of tocopherol-mediated peroxidation $^{51}$ of lipids in human LDL which has been linked to heart disease. 7-Dehydrocholesterol (7-DHC) serves as the biosynthetic precursor to cholesterol, and it plays a central role in one of the most common autosomal recessive human disorders, Smith-Lemli-Opitz syndrome (SLOS). The astonishingly high rate of oxidation of 7-DHC, a value that is greater than the propagation rate constant measured for any other lipid $\left(k_{\mathrm{p}}\right.$ of $2260 \mathrm{M}^{-1} \mathrm{~s}^{-1}$ ), led to the investigation of kinetic isotope effect (KIE) in peroxidation of 7-DHC under tocopherol-mediated peroxidation conditions. ${ }^{52-54}$

9,14- $d_{2}-7-$-DHC (128) was synthesized as shown in Scheme 33. Sonogashira coupling of the deuterated triflate $125^{55}$ and alkyne 126 followed by Lindlar reduction afforded 9,14-dideuteroprevitamin $D_{3}$ (127). Ring $B$ of 9,14- $d_{2}-7-\mathrm{DHC}(\mathbf{1 2 8})$ was closed via a $6 \pi$ conrotatory photocyclization of 127 and the product was isolated from the resulting mixture by preparative HPLC. By monitoring the products formed during a competition reaction, the KIE for the hydrogen (deuterium) atom removal at C-9 was found to be $21 \pm 1$. The unusually large KIE value suggests that it is likely that hydrogen atom transfer in tocopherol-mediated peroxidation of 7$\mathrm{DHC}$ also involves quantum tunneling. ${ }^{56}$ 

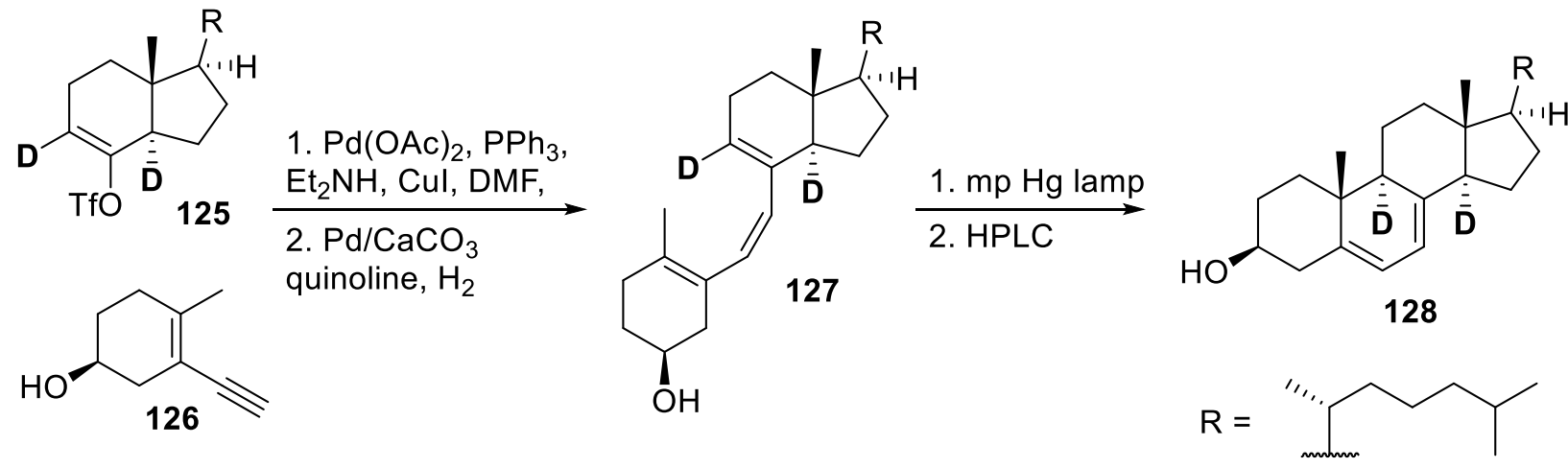

\section{Scheme 33}

\section{Summary}

Sterols labeled with deuterium continue to play a significant role in chemical and biochemical research. Their utility as mechanistic tracers as well as reference compounds for mass spectrometry will remain unchallenged for quite some time. Nevertheless, methods for the synthesis of deuterated sterols did not develop nearly as rapidly. As new catalytic reactions were discovered, and eventually adopted in complex molecule synthesis, approaches to isotope labeling is still carried out, with few exceptions, via deuteride reduction or $\mathrm{H}-\mathrm{D}$ exchange. That usually comes at a significant cost in preparation of precursors, multiple redox operations, and use of protecting groups. The field of selective synthesis of deuterium-enriched sterols remains open for significant contributions and stereoselective $\mathrm{C}-\mathrm{H}(\mathrm{D})$ functionalization methodology ${ }^{57,58}$ seems to be particularly well suited for that task.

\section{References}

1. Matsumori, N.; Tahara, K.; Yamamoto, H.; Morooka, A.; Doi, M.; Oishi, T.; Murata, M., J. Am. Chem. Soc. 2009, 131, 11855-11860.

http://dx.doi.org/10.1021/ja9033473

2. Espiritu, R. A.; Matsumori, N.; Murata, M.; Nishimura, S.; Kakeya, H.; Matsunaga, S.; Yoshida, M., Biochemistry 2013, 52, 2410-2418.

http://dx.doi.org/10.1021/bi4000854

3. Petersson, E. V.; Nahar, N.; Dahlin, P.; Broberg, A.; Tröger, R.; Dutta, P. C.; Jonsson, L.; Sitbon, F., PLoS One 2013, 8, e82955.

http://dx.doi.org/10.1371/journal.pone.0082955

4. Xu, L.; Korade, Z.; Rosado, D. A.; Liu, W.; Lamberson, C. R.; Porter, N. A., J. Lipid Res. 2011, 52, $1222-1233$. http://dx.doi.org/10.1194/jlr.M014498

5. Korade, Z.; Kim, H.-Y. H.; Tallman, K. A.; Liu, W.; Koczok, K.; Balogh, I.; Xu, L.; Mirnics, K.; Porter, N. A., J. Med. Chem. 2016, 59, 1102-1115. http://dx.doi.org/10.1021/acs.jmedchem.5b01696

6. Xu, L.; Porter, N. A., J. Am. Chem. Soc. 2014, 136, 5443-5450. http://dx.doi.org/10.1021/ja5011674 
7. Tökes, L.; Throop, L. J., Introduction of Deuterium into the Steroid System. In Organic Reactions in Steroid Chemistry, Fried, J.; Edwards, J. A., Eds. Van Nostrand Reinhold Company: New York, 1972; Vol. 1, pp 145-221.

8. Shinkyo, R.; Xu, L.; Tallman, K. A.; Cheng, Q.; Porter, N. A.; Guengerich, F. P., J. Biol. Chem. 2011, 286, 33021-33028.

http://dx.doi.org/10.1074/ibc.M111.282434

9. Fujimoto, Y.; Kushiro, T.; Nakamura, K., Tetrahedron Lett. 1997, 38, 2697-2700. http://dx.doi.org/10.1016/S0040-4039(97)00432-2

10. Godin, J.-P.; Richelle, M.; Metairon, S.; Fay, L.-B., Rapid Commun. Mass Spectrom. 2004, 18, 325-330. http://dx.doi.org/10.1002/rcm.1336

11. Bloch, K.; Rittenberg, D., J. Biol. Chem. 1943, 149, 505-509.

12. Anker, H. S.; Bloch, K., J. Am. Chem. Soc. 1944, 66, 1752-1755.

http://dx.doi.org/10.1021/ja01238a040

13. Fukushima, D. K.; Lieberman, S.; Praetz, B., J. Am. Chem. Soc. 1950, 72, 5205-5211. http://dx.doi.org/10.1021/ja01167a118

14. Dodson, R. M.; Riegel, B., J. Org. Chem. 1948, 13, 424-437. http://dx.doi.org/10.1021/jo01161a018

15. Corey, E. J.; Sneen, R. A., J. Am. Chem. Soc. 1956, 78, 6269-6278. http://dx.doi.org/10.1021/ja01605a013

16. Ireland, R. E.; Wrigley, T. I.; Young, W. G., J. Am. Chem. Soc. 1958, 80, 4604-4606. http://dx.doi.org/10.1021/ja01550a047

17. Ireland, R. E.; Wrigley, T. I.; Young, W. G., J. Am. Chem. Soc. 1959, 81, 2818-2821. http://dx.doi.org/10.1021/ja01520a050

18. Jones, D. N.; Lewis, J. R.; Shoppee, C. W.; Summers, G. H. R., Journal of the Chemical Society (Resumed) 1955, 2876-2887. http://dx.doi.org/10.1039/JR9550002876

19. Malhotra, S. K.; Ringold, H. J., J. Am. Chem. Soc. 1964, 86, 1997-2003. http://dx.doi.org/10.1021/ja01064a018

20. Nambara, T.; Ikegawa, S.; Hirayama, T.; Hosoda, H., Chem. Pharm. Bull. 1977, 25, 3093-3096. http://dx.doi.org/10.1248/cpb.25.3093

21. Jones, D. N.; Knox, S. D., J. Chem. Soc., Chem. Commun. 1975, 165-166. http://dx.doi.org/10.1039/C39750000165

22. Collins, D.; Jackson, W.; Timms, R., Aust. J. Chem. 1980, 33, 2663-2672. http://dx.doi.org/10.1071/CH9802663

23. Rabinowitz, M. H., Tetrahedron Lett. 1991, 32, 6081-6084. http://dx.doi.org/10.1016/0040-4039(91)80758-X

24. Achmatowicz, S.; Barton, D. H. R.; Magnus, P. D.; Poulton, G. A.; West, P. J., J. Chem. Soc., Perkin Trans. 1 1973, 1567-1570.

http://dx.doi.org/10.1039/P19730001567

25. Viger, A.; Coustal, S.; Marquet, A., Tetrahedron 1978, 34, 3285-3290. http://dx.doi.org/10.1016/0040-4020(78)80246-4

26. Viger, A.; Marquet, A.; Barton, D. H. R.; Motherwell, W. B.; Zard, S. Z., J. Chem. Soc., Perkin Trans. 1 1982, 1937-1940. 
27. Šolaja, B. A.; Milić, D. R.; Došen-Mićović, L. I., Steroids 1994, 59, 330-334.

http://dx.doi.org/10.1016/0039-128X(94)90122-8

28. Nambara, T.; Ikegawa, S.; Ishizuka, T.; Goto, J., Chem. Pharm. Bull. 1974, 22, 2656-2661.

http://dx.doi.org/10.1248/cpb.22.2656

29. Seo, S.; Yoshimura, Y.; Satoh, T.; Uomori, A.; Takeda, K. i., J. Chem. Soc., Perkin Trans. 1 1986, 411-414. http://dx.doi.org/10.1039/P19860000411

30. Uomori, A.; Seo, S.; Sato, T.; Yoshimura, Y.; Takeda, K. i., J. Chem. Soc., Perkin Trans. 1 1987, 1713-1718. http://dx.doi.org/10.1039/P19870001713

31. Lund, E.; Breuer, O.; Björkhem, I., J. Biol. Chem. 1992, 267, 25092-25097.

32. Corey, E. J.; Grogan, M. J., Tetrahedron Lett. 1998, 39, 9351-9354.

http://dx.doi.org/10.1016/S0040-4039(98)02181-9

33. Takahashi, K.; Hashimoto, K.; Fujiyama, A.; Yamada, J.; Kobayashi, N.; Morisaki, M.; Nakano, S.; Hara, N.; Fujimoto, Y., Tetrahedron Lett. 2003, 44, 341-344.

http://dx.doi.org/10.1016/S0040-4039(02)02567-4

34. Diekman, J.; Djerassi, C., J. Org. Chem. 1967, 32, 1005-1012.

http://dx.doi.org/10.1021/jo01279a033

35. Wyllie, S. G.; Amos, B. A.; Tokes, L., J. Org. Chem. 1977, 42, 725-732.

http://dx.doi.org/10.1021/jo00424a033

36. Malhotra, S. K.; Ringold, H. J., J. Am. Chem. Soc. 1963, 85, 1538-1539.

http://dx.doi.org/10.1021/ja00893a035

37. Klein, H.; Djerassi, C., Chem. Ber. 1973, 106, 1897-1904.

http://dx.doi.org/10.1002/cber.19731060619

38. Throop, L. J.; Tokes, L., J. Am. Chem. Soc. 1967, 89, 4789-4790.

http://dx.doi.org/10.1021/ja00994a041

39. Gruenke, L. D.; Craig, J. C., J. Labelled Compd. Radiopharm. 1979, 16, 495-500.

http://dx.doi.org/10.1002/ilcr.2580160316

40. Raab, K. H.; De Souza, N. J.; Nes, W. R., Biochimica et Biophysica Acta (BBA) - Lipids and Lipid Metabolism 1968, 152, 742-748.

http://dx.doi.org/10.1016/0005-2760(68)90120-3

41. Zhou, W.; Guo, D.-a.; Nes, W. D., Tetrahedron Lett. 1996, 37, 1339-1342.

http://dx.doi.org/10.1016/0040-4039(96)00017-2

42. Kirk, D. N.; Varley, M. J.; Makin, H. L. J.; Trafford, D. J. H., J. Chem. Soc., Perkin Trans. 1 1983, 2563-2567. http://dx.doi.org/10.1039/P19830002563

43. Holm, T.; Crossland, I., J. Labelled Compd. Radiopharm. 1996, 38, 803-808. http://dx.doi.org/10.1002/(SICI)1099-1344(199609)38:9\%3C803::AID-JLCR892\%3E3.0.CO;2-R

44. Wasilchuk, B. A.; Le Quesne, P. W.; Vouros, P., Anal. Chem. 1992, 64, 1077-1087.

http://dx.doi.org/10.1021/ac00034a003

45. Ciuffreda, P.; Casati, S.; Alessandrini, L.; Terraneo, G.; Santaniello, E., Steroids 2003, 68, 733-738. http://dx.doi.org/10.1016/S0039-128X(03)00116-8

46. Chu, G.-H.; Li, P.-K., J. Labelled Compd. Radiopharm. 2000, 43, 773-779. http://dx.doi.org//10.1002/1099-1344(200007)43:8<773::AID-JLCR361>3.0.CO;2-G

47. Baek, D. J.; Bittman, R., Chem. Phys. Lipids 2013, 175-176, 99-104.

http://dx.doi.org/10.1016/i.chemphyslip.2013.08.003 
48. Miura, Y.; Hui, S.-P.; Shrestha, R.; Hiruma, T.; Takeda, S.; Fuda, H.; Ikegawa, S.; Hirano, K.-i.; Chiba, H., Steroids 2016, 107, 1-9.

http://dx.doi.org/10.1016/i.steroids.2015.12.004

49. Nising, C. F.; Bräse, S., Angew. Chem. Int. Ed. 2008, 47, 9389-9391.

http://dx.doi.org/10.1002/anie.200803720

50. Belani, J. D.; Rychnovsky, S. D., J. Org. Chem. 2008, 73, 2768-2773.

http://dx.doi.org/10.1021/jo702694g

51. Lamberson, C. R.; Xu, L.; Muchalski, H.; Montenegro-Burke, J. R.; Shmanai, V. V.; Bekish, A. V.; McLean, J. A.; Clarke, C. F.; Shchepinov, M. S.; Porter, N. A., J. Am. Chem. Soc. 2014, 136, 838-841.

http://dx.doi.org/10.1021/ja410569g

52. Porter, F. D.; Herman, G. E., J. Lipid Res. 2011, 52, 6-34.

http://dx.doi.org/10.1194/ilr.R009548

53. Porter, N. A., J. Org. Chem. 2013, 78, 3511-24.

http://dx.doi.org/10.1021/jo4001433

54. Xu, L.; Korade, Z.; Porter, N. A., J. Am. Chem. Soc. 2010, 132, 2222-2232.

http://dx.doi.org/10.1021/ja9080265

55. Maestro, M. A.; Sardina, F. J.; Castedo, L.; Mourino, A., J. Org. Chem. 1991, 56, 3582-3587. http://dx.doi.org/10.1021/jo00011a024

56. Muchalski, H.; Xu, L.; Porter, N. A., Org. Biomol. Chem. 2015, 13, 1249-1253.

http://dx.doi.org/10.1039/C4OB02377C

57. Davies, H. M. L.; Morton, D., J. Org. Chem. 2016, 81, 343-350.

http://dx.doi.org/10.1021/acs.joc.5b02818

58. Liao, K.; Negretti, S.; Musaev, D. G.; Bacsa, J.; Davies, H. M. L., Nature 2016, 533, 230-234. http://dx.doi.org/10.1038/nature17651

\section{Author's Biography}

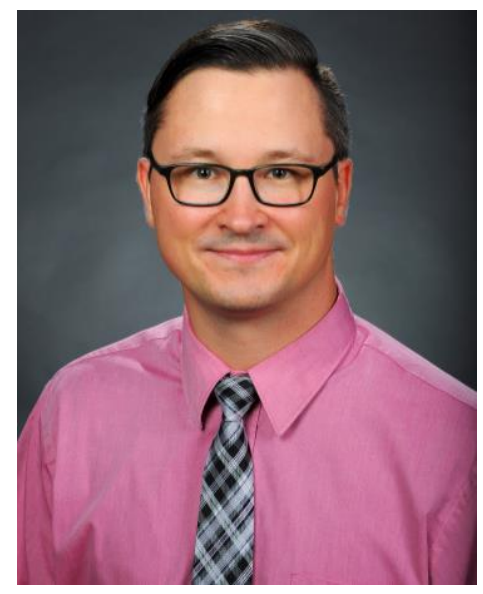

Hubert Muchalski graduated from Wroclaw University of Technology in 2006. During his studies, he worked in the group led by Prof. Jacek Młochowski investigating the diselenide catalyzed hydroperoxide oxidation of naphthalenes. In 2006, he moved to Nashville, TN to begin graduate studies at Vanderbilt University the group of Prof. Jefferey N. Johnston where he worked on two-directional total synthesis of antibiotic (+)-zwittermicin A. After a postdoctoral appointment with Prof. Ned A. Porter, he joined California State University, Fresno as 
an Assistant Professor of Chemistry. His scientific interests are related to lipid peroxidation and isotopic labeling of polyunsaturated fatty acids and sterols. 